\title{
Experimental and Steady-RANS CFD Modelling of Cross- ventilation in Moderately-dense Urban Areas
}

\begin{abstract}
Computational fluid dynamics (CFD) models based on the steady Reynolds-averaged Navier Stokes (SRANS) equations are vastly used for calculation of airflow field inside and around cross-ventilated buildings. However, most of the developed CFD guidelines ignore CFD challenges related to cross-ventilation modeling in terms of flow unsteadiness, high level of gradients of airflow parameters, and complex interactions between the indoor and outdoor flows.

Hence, a systematic parametric study was performed in this study for a generic crossventilated building model with a planar area ratio of 0.25 against different wind angles while effects of different CFD parameters, including advection and diffusion terms discretization methods, mesh generation techniques, and turbulence models on prediction accuracy and convergence behavior of CFD solver were comprehensively studied.

Results show that a particularly generated unstructured tetrahedral mesh configuration with significantly lower mesh numbers can provide comparable results with structured hexahedral mesh configuration. Furthermore, second-order discretization scheme for advection terms encounters convergence issues against the normal wind angle, but generally presents more accurate results against oblique wind angles. Moreover, twoequation turbulence models showed very low accuracy in the case of normal wind angle, but acceptable results were found for oblique wind angles.
\end{abstract}

Keywords: Cross-ventilation, CFD, wind surface pressure, airflow rate, urban area, sheltered condition

\section{Introduction}

Computational fluid dynamics (CFD) models are powerful approaches to tackle different aspects of urban studies with their reasonable advantages in flexibility and accuracy. In specific, CFD models have been extensively used for evaluation and analysis of building energy (Allegrini \& Carmeliet, 2017; Allegrini, Dorer, \& Carmeliet, 2015; Charisi, Waszczuk, \& Thiis, 2019; Malys, Musy, \& Inard, 2015; Akashi Mochida, Yoshino, Miyauchi, \& Mitamura, 2006; Phan \& Lin, 2019; Mohammadreza Shirzadi, Naghashzadegan, \& Mirzaei, 2019; Tong, Chen, \& Malkawi, 2016; Zhang, Mirzaei, \& Jones, 2018), urban heat island mitigation (Kurbatskii, 2001; Mirzaei \& Haghighat, 2012), pollution dispersion in cities (Mirzaei \& Haghighat, 2011; Tominaga \& Stathopoulos, 2011, 2017, 2018), wind energy utilization (Mirzaei \& Rad, 2013), mesoscale meteorological simulation (Yamamoto, Kasai, Okaze, Hanaoka, \& Mochida, 2018), pedestrian comfort (Iqbal \& Chan, 2016; Ishida, Okaze, \& Mochida, 2018; Liu, Heidarinejad, Pitchurov, 
Zhang, \& Srebric, 2018), and sand erosion (Tominaga, Okaze, \& Mochida, 2018). Despite the increasing popularity of CFD models and their noticeable lower cost in comparison with wind tunnel and field measurements, in terms of implementation and time, their accuracy for wind related studies in urban areas are limited (M. Shirzadi, Mirzaei, \& Naghashzadegan, 2017; M. Shirzadi, Mirzaei, Naghashzadegan, \& Tominaga, 2018). In particular, CFD models provide potential tools to study the utilization of natural ventilation for building energy reduction and indoor thermal comfort improvement (Indraganti, 2010; Akashi Mochida, Yoshino, Takeda, Kakegawa, \& Miyauchi, 2005; M. Shirzadi, Mirzaei, \& Naghashzadegan, 2018; M. Shirzadi, Naghashzadegan, \& A. Mirzaei, 2018). Nonetheless, the airflow structure around and inside a cross-ventilated building is very complex, which includes boundary layer separation and reattachment, vortex shedding (A Mochida et al., 2002; Murakami, Mochida, \& Hayashi, 1990), large scale velocity fluctuation (Tominaga, 2015), and highly transient phenomena such as flapping jet (Tominaga \& Blocken, 2015). These complex structures make CFD simulations very challenging to resolve airflow details, particularly in dense urban areas where many of these phenomena coexist together.

Accuracy of CFD models based on the steady Reynolds-averaged Navier-Stokes (SRANS) equations for prediction of airflow distribution inside isolated buildings was shown to be very promising for different opening sizes and positions (M. Shirzadi, Mirzaei, \& Naghashzadegan, 2018; M. Shirzadi, Mirzaei, Naghashzadegan, et al., 2018; van Hooff, Blocken, \& Tominaga, 2017). In contrast to the unsheltered building, the accuracy of steady RANS models is questionable for the case of cross-ventilated buildings in sheltered condition. Low accuracy of SRANS models is contributed to their inherent incapability in reproducing the transient fluctuations caused by the vortex shedding around buildings, poor estimation of the momentum diffusion in the wake region behind buildings (Tominaga, Akabayashi, Kitahara, \& Arinami, 2015), and the uncertainty of the closure coefficients of the turbulence models utilized for atmospheric boundary layer (ABL) flows (M. Shirzadi et al., 2017; M. Shirzadi, Mirzaei, Naghashzadegan, et al., 2018). These deficiencies result in a poor estimation of velocity and turbulent kinetic energy (TKE) distributions in the wake region formed between the buildings in urban areas, which consequently result in low accurate estimations of cross-ventilation by SRANS models for moderately- and highly-packed building arrangements.

Furthermore, despite the superiority of LES and URANS models over the SRANS models in prediction of the airflow and wind surface pressure distributions for sheltered cross-ventilated buildings in moderately-dense urban areas (King et al., 2017), the noticeable computational cost and complexity in boundary condition implementation of these models make them impractical for many engineering applications in urban studies where a large computational domain with numerous buildings are required. Moreover, LES and URANS, showed a significantly weaker performance in highly-dense urban areas. For example, comparison of the drag coefficient over a sheltered building model using LES reported by (Razak, Hagishima, Ikegaya, \& Tanimoto, 2013) and (Kanda, 2006) showed a noticeable large deviation of about $45 \%$ for building arrangements with urban planar area ratios of more than 0.25 . In contrast, the deviation between the predicted results of the velocity profile and drag coefficient by (Razak et al., 2013) and (Kanda, 2006) is very low for urban planar area ratio of 0.25 . 
Considering these limitations, it is obvious that CFD models based on SRANS turbulence models are still the most applicable and popular ones for engineering applications in urban studies during design phase and even in research studies. Despite this high implementation of SRANS models, there is a clear lack of detailed study about the accuracy of such models for different building configurations and sheltering conditions. Moreover, a constant wind angle was mainly considered in most studies while the performance and accuracy of CFD models should be studies in detail against different wind angles. Furthermore, most CFD guidelines were developed for outdoor flow around buildings while cross-ventilation, which has more challenging issues for numerical calculations such is high level of flow gradients, complex interactions between the indoor and outdoor flows, and high level of flow unsureness, is not generally addressed in the CFD guidelines.

Hence, a framework is established in this study to conduct a series of wind tunnel experimental measurements and numerical simulations on cross-ventilation in sheltered buildings with generic forms against different wind angles. The aim of this paper is to investigate the accuracy and limitations of SRANS turbulence models in prediction of cross-ventilation for a simplified building model in different sheltering conditions allocated in moderately-packed urban configurations. To this end, numerical results were compared with the wind tunnel experimental results conducted by authors against different wind angles. Moreover, the instability and convergence problem of CFD models as well as their accuracy are studied in details for different parameters, including advection and diffusion terms discretization methods, mesh generation techniques, and turbulence models. Outlines of wind tunnel experiments and numerical modelling are presented in section 2 and 3 . Results are analyzed in section 4 and finally conclusions are discussed in section 5 .

\section{Outlines of wind tunnel experiments}

\subsection{Wind tunnel specification and building arrangements}

Experimental measurements were conducted in the atmospheric wind tunnel at the Niigata Institute of Technology (NIIT), Japan (Akabayashi, Mochida, Tominaga, Yoshida, \& Sakaguchi, 1996; Tominaga et al., 2008; Tominaga \& Stathopoulos, 2011; Yoshie et al., 2007). The test section has dimensions of $1.8 \mathrm{~m} \times 1.8 \mathrm{~m} \times 13 \mathrm{~m}$ in which a neutral boundary layer profile was generated using roughness elements. The mean streamwise velocity $\left(U_{H}\right)$ and TKE $(k)$ profiles

are shown in (a) and can be approximated by the following equations in which $U_{H}=5.233 \frac{\mathrm{m}}{\mathrm{s}}$ is the mean streamwise velocity at the reference height of $H=0.16 \mathrm{~m}$ :

$$
\begin{aligned}
\frac{U(z)}{U_{H}} & =\left(\frac{z}{H}\right)^{0.25} \\
\frac{k(z)}{U_{H}{ }^{2}} & =0.033 \exp ^{-0.32(z / H)}
\end{aligned}
$$

The roughness Reynolds number, aerodynamic roughness, and friction velocity of the wind tunnel were found to be respectively $R e=8.0, z_{0}=0.00033 \mathrm{~m}$, and $u^{*}=0.33 \frac{\mathrm{m}}{\mathrm{s}}$ (Tominaga et al., 2008). Nine buildings with dimensions of $0.2 \mathrm{~m} \times 0.2 \mathrm{~m} \times 0.16 \mathrm{~m}(B \times D \times H)$ in a regular arrangement were considered with a planar area ratio of $\lambda_{P}=0.25$. The planar area ratio is defined as (Quan et al., 2007): 


$$
\lambda_{P}=\frac{B D}{(B+W)(D+W)}
$$

where $B$ and $D$ are respectively building's breadth and depth. $W$ is the distance between buildings which is set as $0.200 \mathrm{~m}$ at the planar area ratio of 0.25 (see Figure 1(b)). The central building was ventilated through two openings at building's mid height on opposite walls with dimensions of $0.036 \mathrm{~m} \times 0.092 \mathrm{~m}$ while surrounding buildings had no opening. Different examined by rotating the turntable in the clockwise direction around $z$ axis (se

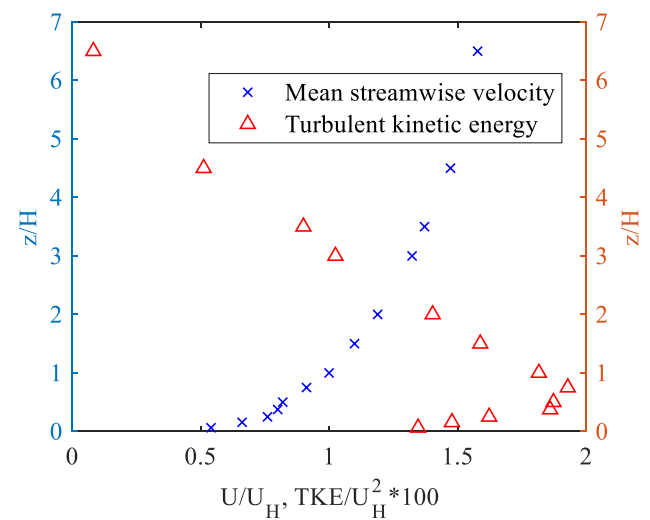

(a)
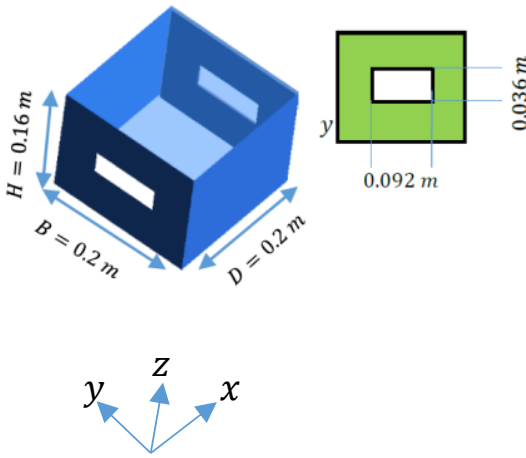

(b)

Figure 1 a) Vertical profiles of the mean streamwise velocity and TKE at the center of the empty turntable, b) building arrangements and dimensions

\subsection{Measurement parameters and techniques}

Wind tunnel experiment was conducted to measure the instantaneous velocity vector, wind surface pressures, and crossing airflow rates. The wind velocity components were measured over a vertical central plane inside the target building and two vertical planes in the upstream and downstream cavities around the target building (see Figure 2(a)). A constant temperature anemometry (CTA) module (Dantec Dynamics; 90C10) with a split fiber probe (SFP) sensor (Dantec Dynamics; 55R55) was used for the velocity measurements. The sampling rate was set to $100 \mathrm{~Hz}$ over a 60 seconds time-averaging period to obtain statistically stationary data.

A multi-point pressure transducer (Kyowa Electronic Instruments; F94-2206) (Tominaga et al., 2015) was used for wind pressure measurements over eight pressure taps around the windward and leeward openings and three pressure taps at the center of internal walls (side walls and ceiling) as shown in Figure 2(b). The pressure tubes were attached to the building walls in order to reduce a potential internal blockage caused by the pressure tubes. A sampling rate of $100 \mathrm{~Hz}$ and a sampling time of 60 seconds were considered while all measurements were repeated four times for each case. The surface-averaged wind pressure coefficients for the windward $\left(C_{P}^{w w}\right)$, leeward $\left(C_{P}^{l w}\right)$, and internal surfaces $\left(C_{P}^{\text {int }}\right)$ are calculated as bellow:

$$
\overline{C_{P}^{w w}}=\frac{1}{4} \sum_{i=1}^{4} \frac{P_{i}^{w w}-P_{r e f}}{\frac{1}{2} \rho U_{H}^{2}}
$$




$$
\begin{aligned}
& \overline{C_{P}^{l w}}=\frac{1}{4} \sum_{i=1}^{4} \frac{P_{i}^{l w}-P_{\text {ref }}}{\frac{1}{2} \rho U_{H}^{2}} \\
& \overline{C_{P}^{l n t}}=\frac{1}{3} \sum_{i=1}^{3} \frac{P_{i}^{i n t}-P_{r e f}}{\frac{1}{2} \rho U_{H}^{2}}
\end{aligned}
$$

where $P_{i}^{w w}, P_{i}^{l w}$, and $P_{i}^{\text {int }}$ are respectively the measured local pressures over windward façade, leeward façade, and internal walls. $P_{r e f}$ and $\rho$ are the reference pressure and air density, respectively.

In order to compare the surface wind pressure obtained by CFD models with experimental data, it is reasonable to compare the pressure differences over the building walls instead of comparing the pressure coefficients. This is due to the fact that a difficult procedure is required to find the suitable location for the reference pressure calculation used in the pressure coefficient definition (Montazeri \& Blocken, 2013). Hence, the following surface pressure differences are defined for the comparison study:

$$
\begin{aligned}
& \Delta C_{P}^{w w}=\overline{C_{P}^{w w}}-\overline{C_{P}^{l n t}} \\
& \Delta C_{P}^{l w}=\overline{C_{P}^{l n t}}-\overline{C_{P}^{l w}} \\
& \Delta C_{P}^{\text {total }}=\overline{C_{P}^{w w}}-\overline{C_{P}^{l w}}
\end{aligned}
$$

where $\Delta C_{P}^{w w}$ and $\Delta C_{P}^{l w}$ are respectively the windward and leeward pressure difference coefficients and $\Delta C_{P}^{\text {total }}$ is the total pressure difference coefficient.

Airflow rate measurement was conducted by the tracer gas method in which Ethylene was utilized as the tracer gas which was injected through the windward opening at a constant flow rate of $q_{\text {Ethylene }}=2 \frac{\mathrm{L}}{\mathrm{min}}$. The mean concertation near the leeward opening $\left(\overline{C_{\text {outlet }}}\left[\frac{\mathrm{m}^{3}}{\mathrm{~m}^{3}}\right]\right)$ was measured by using a high-speed total hydrocarbon analyzer (Technica, HTHCA-01). The crossing airflow rate $\left(q_{o}\left[\frac{m^{3}}{s}\right]\right)$ is calculated as follows:

$$
q_{o}=\frac{q_{\text {Ethylene }}}{\overline{C_{\text {outlet }}}}
$$

All measurements were repeated several times while data were measured for a sampling time of $60 s$. 


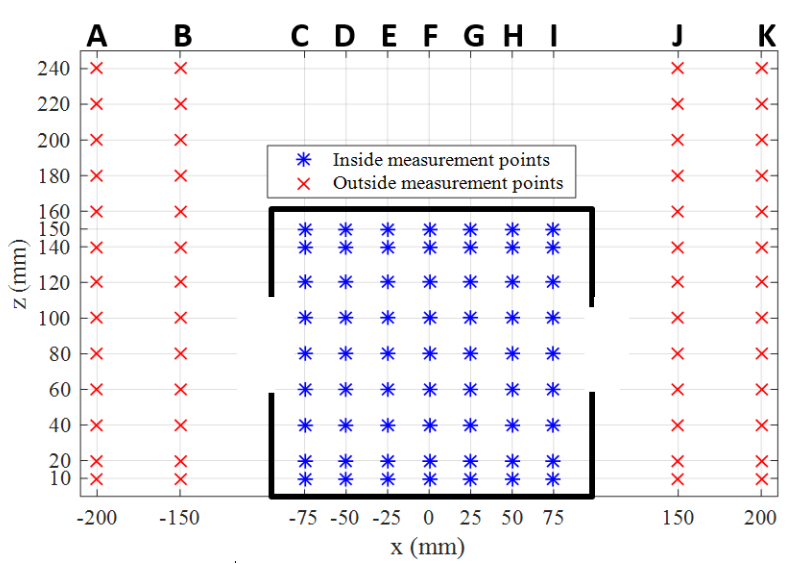

(a)

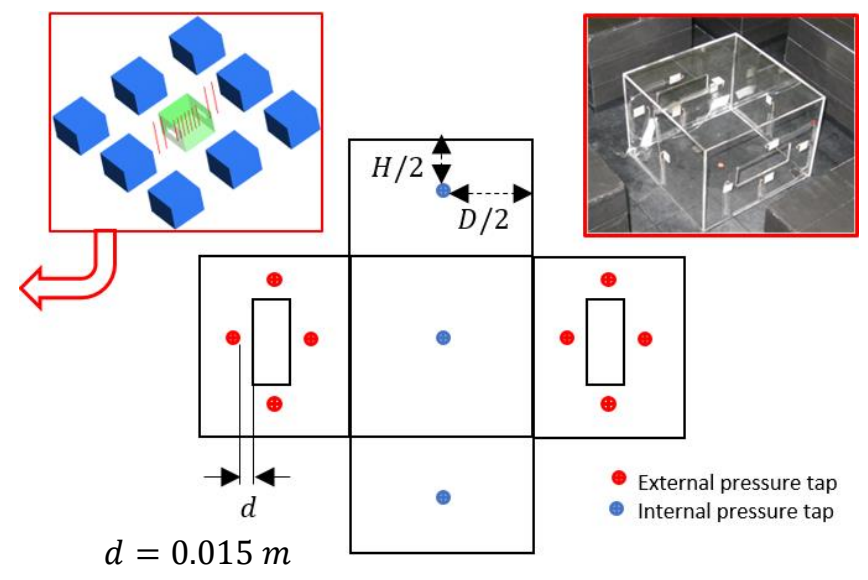

(b)

Figure 2 Location of velocity and wind pressure measurements

\section{Outlines of numerical modeling}

\subsection{Computational domain and boundary conditions}

A schematic of the computational domain is shown in Figure 3(a) which was generated based on the recommendations by AIJ guidelines (Tominaga et al., 2008). The dimensions of the computational domain's width, length, and height are $1.8 \mathrm{~m} \times 4.48 \mathrm{~m} \times 1.8 \mathrm{~m}$. The computational domain was stretched up to the wind tunnel side walls and roof. Inlet boundary condition for the streamwise velocity and TKE were implemented using the measured wind tunnel profiles. The TKE dissipation rate $(\varepsilon)$ and its specific dissipation $(\omega)$ were calculated by the following equations, assuming an equilibrium between TKE production and dissipation rate (Tominaga, 2015):

$$
\begin{aligned}
& \varepsilon(z)=C_{\mu}^{\frac{1}{2}} k(z) \frac{U_{H}}{H} \alpha\left(\frac{Z}{H}\right)^{\alpha-1} \\
& \omega=\varepsilon \frac{C_{\mu}}{k}
\end{aligned}
$$

where $\mathrm{C}_{\mu}=0.09$ denotes the model constant and $\alpha=0.25$ is the power-law exponent.

For all simulations, a fixed inlet boundary condition was considered because effects of inlet boundary condition on CFD accuracy were extensively studied in (Ramponi \& Blocken, 2012b, 2012a). For the building surfaces, wind tunnel ceiling, and side walls, a smooth solid surface boundary condition was considered while a constant pressure was assumed over the outlet boundary.

\subsection{Grid settings}

Two different grid settings were studied in order to find an optimum grid distribution, which not only provides accurate results, but also requires a minimum meshing effort and simulation run time. The first mesh setting, namely Mesh A, is an unstructured tetrahedral mesh created by 
ANSYS Mesh while the second mesh, namely Mesh B, is a structured hexahedral mesh generated by ANSYS ICEM CFD using the blocking technique. Application of the hexahedral mesh is recommended by (Blocken, 2015; Franke et al., 2004), stating that it yield smaller truncation errors and better iterative convergence in comparison with the tetrahedral mesh. For the mesh study, three mesh models were created as coarse, medium, and fine meshes for both Mesh A and Mesh B. The number of cells for the structured hexahedral mesh setting (Mesh B) were $3,761,565,5,876,911$, and 9,209,313 for the coarse, medium, and fine meshes, respectively. For the unstructured tetrahedral mesh setting (Mesh A), a noticeably lower number of cells were intentionally considered with 967,829, 1,223,727, and 2,074,270 for coarse, medium, and fine meshes, respectively. The difference in the velocity and TKE predictions by different meshes were investigated and the medium mesh setting was found to be appropriate for both cases. An emptydomain test was conducted for both mesh settings to investigate the consistency of the generated meshes and implemented boundary conditions in reproducing the $A B L$ horizontal homogeneity along the computational domains. The incident profiles of the streamwise velocity by both mesh settings were obtained to be very similar to the inlet profile.

Details of Mesh A and Mesh B for medium setting are shown in Table 1 and Table 2, respectively. The number of divisions on the buildings and openings edges is almost the same for both meshes. In the unstructured tetrahedral mesh (Mesh A), the mesh density was high inside the crossventilated building with an element size of volume meshes of $0.008 \mathrm{~m}$ while it was coarsened in regions far from the building, reaching to a value of $0.08 \mathrm{~m}$. This was also similar for the element size of face (surface) meshes, which was increased from $0.008 \mathrm{~m}$ for the building walls to $0.08 \mathrm{~m}$ for the wind tunnel walls. In this way, a lower number of computational cells were generated in comparison with the structured hexahedral mesh (Mesh B). The boundary layer mesh over all solid surfaces (i.e., buildings' and wind tunnel's walls) was created using prism elements with the first layer height of $10^{-4} \mathrm{~m}$ and in 15 layers (see Figure 3(c)).

\begin{tabular}{|c|c|c|c|c|c|c|c|c|c|c|}
\hline No. nodes & $\begin{array}{l}\text { No. divisions on } \\
\text { openings' edges }\end{array}$ & \multicolumn{2}{|c|}{$\begin{array}{l}\text { No. divisions on } \\
\text { buildings' edges }\end{array}$} & $\begin{array}{c}\text { Face mesh size } \\
\text { of building walls } \\
\text { ground }\end{array}$ & \multicolumn{2}{|c|}{$\begin{array}{l}\text { Face mesh } \\
\text { size of wind } \\
\text { tunnel walls }\end{array}$} & $\begin{array}{l}\text { Volume mesh } \\
\text { size inside the } \\
\text { target building }\end{array}$ & \multicolumn{2}{|c|}{$\begin{array}{l}\text { Volume mesh size inside } \\
\text { the wind tunnel }\end{array}$} & First layer high \\
\hline $1,223,727$ & $30 \times 25$ & \multicolumn{2}{|l|}{35} & $0.008 \mathrm{~m}$ & \multicolumn{2}{|c|}{$0.08 \mathrm{~m}$} & $0.008 \mathrm{~m}$ & & $0.08 m$ & $10^{-4} \mathrm{~m}$ \\
\hline \multicolumn{11}{|c|}{ Table 2 Mesh parameters for the structured hexahedral mesh setting (Mesh B) } \\
\hline No. nodes & \multicolumn{2}{|c|}{$\begin{array}{c}\text { No. divisions on openings' } \\
\text { edges }\end{array}$} & \multicolumn{3}{|c|}{$\begin{array}{c}\text { No. divisions on surrounding } \\
\text { buildings edges }\end{array}$} & \multicolumn{3}{|c|}{$\begin{array}{c}\text { No. divisions on target } \\
\text { building edges }\end{array}$} & \begin{tabular}{|c|} 
No. divisions on \\
wind tunnel edges
\end{tabular} & First layer high \\
\hline $5,876,911$ & \multicolumn{2}{|c|}{$25 \times 20$} & \multicolumn{3}{|c|}{$35 \times 35 \times 60$} & \multicolumn{3}{|c|}{$45 \times 65 \times 60$} & $106 \times 60 \times 105$ & $10^{-4} \mathrm{~m}$ \\
\hline
\end{tabular}

In the structured hexahedral mesh (Mesh B), the blocking technique was used to create a set of blocks around and inside the buildings, which then were used to create structured hexahedral meshes. This process was very time consuming and could be very challenging for complex geometries. In the blocking technique, the mesh distribution over buildings' vertical walls was extruded in a direction perpendicular to the ground all over the computational domain (see Figure $3(d)$ ). This resulted in regions with unnecessary high cell densities and consequently in an increased number of the cells relative to Mesh A. A total number of 15 layers with the first layer height of $10^{-4} \mathrm{~m}$ were considered in the boundary layer mesh over the solids walls (see Figure $3(d)$ ). 


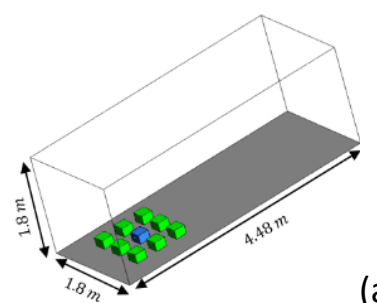

(a)

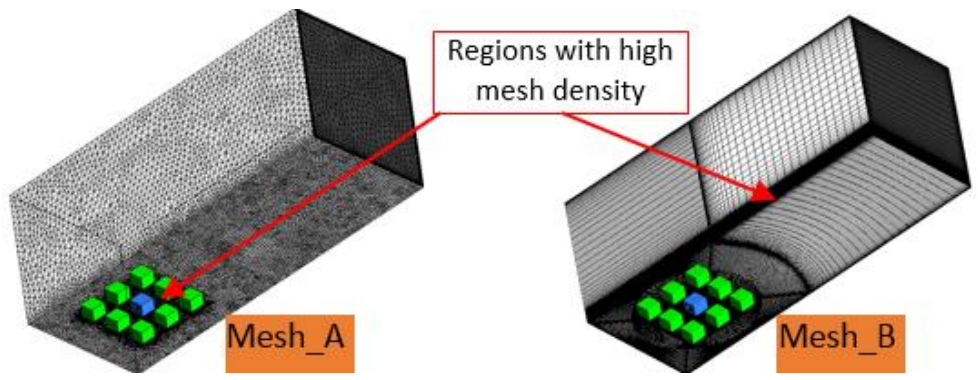

(b)
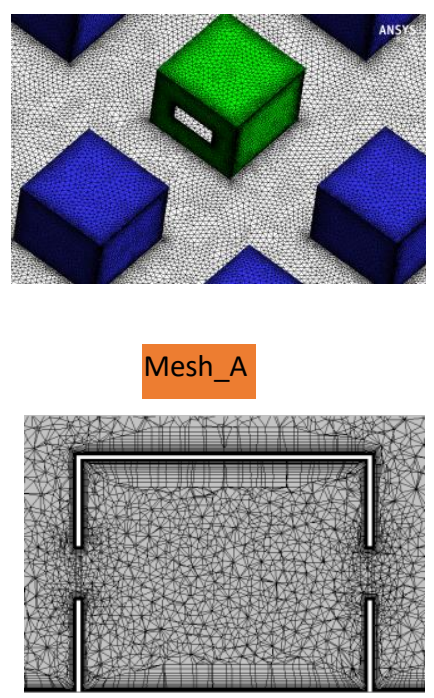

(c)
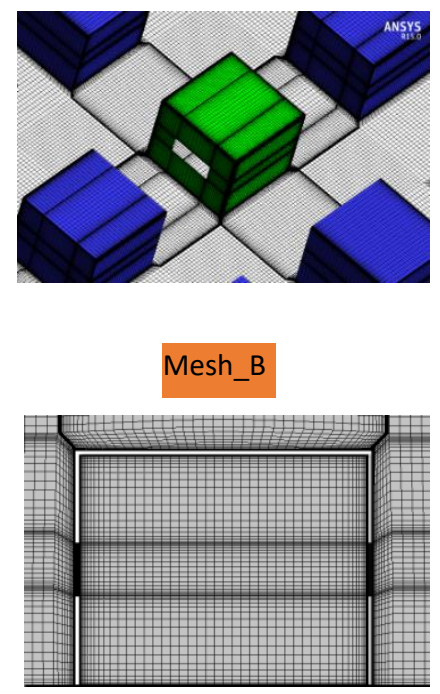

(d)

Figure 3 (a) Computational domain, and the distribution of computational cells on (b) wind tunnel surfaces, and around and inside the building for (c) the unstructured tetrahedral and (d) structured hexahedral mesh settings

In order to generate computational mesh against different wind angles, the orientation of buildings was defined as a variable parameter in ANSYS Workbench and then for each wind angle, a same setting, as described above, was applied. Mesh A can be generated automatically, thanks to the simpler implementation of the unstructured tetrahedral mesh solver in comparison with the structured hexahedral Mesh B, which requires more manipulations on the meshing solver against each wind angle. This is an advantage of the unstructured tetrahedral mesh setting, which noticeably reduces the required time for mesh generation against different wind angles.

\subsection{CFD solver settings}

The SRANS equations were used for discretization of the governing equations for conservation of mass and momentum by using the ANSYS CFX solver. Three commonly used two-equation turbulence models, including the standard $k-\varepsilon$ (Launder \& Spalding, 1974), RNG $k-\varepsilon$ (Yakhot \& Orszag, 1986), and $k-\omega$ SST (Menter, 1994), were considered in this study. While the application of zero-equation models for outdoor pedestrian wind simulations was reported to be accurate and time efficient (Liu et al., 2018), results of further simulations showed that the zeroequation models are inaccurate for cross-ventilation calculations and hence are excluded in this study. Furthermore, application of turbulence models based on Reynold-stress models encounters significant convergence challenges for cross-ventilated buildings in sheltered conditions (M. Shirzadi, Mirzaei, Naghashzadegan, et al., 2018).

A co-located grid layout was used for all transport equations while a modified Rhie and Chow method (Chow \& Rhie, 1982) was used for pressure-velocity coupling. Two different discretization methods were utilized for diffusion terms, including Tri-linear and Linear-linear interpolation formulations. In ANSYS CFX, the default option for the pressure interpolation is Linear-linear, but the default of velocity interpolation is Tri-linear formulation. Linear-linear formulation is more robust than Tri-linear formulation, but it introduces more spatial discretization 
error into the solution (CFX, 2011). Performances of both formulations were investigated for the cross-ventilation modeling and it was found that the diffusion discretization does not have a significant effect on prediction accuracy of the CFD models. Despite of a slightly better convergence observed for Mesh B with Linear-linear formulation against the normal wind angle, Tri-linear formulation was considered in all simulations.

Advection terms were discretized using the first-order upwind differencing scheme (UP) and Hybrid scheme (HR), which is a second-order advection scheme in the low variable gradient regions although it changes to the first-order advection scheme in regions where the gradients rapidly change. The CFX default for the turbulence equations is the first-order UP scheme while the HR scheme is used for the continuity and momentum equations. The first-order UP scheme has a robust convergence performance in expense of adding more diffusive discretization error (CFX, 2011; Ramponi \& Blocken, 2012b, 2012a; Yoshie et al., 2007).

CFX solver is a coupled fully implicit code and uses a multi-grid accelerated incomplete lower upper (ILU) factorization technique for solving the discrete system of linearized equations (CFX, 2011). The steady state solution was achieved through a transient solution strategy in which a false time-step was applied in the CFX solver. Hence, a time-scale is required for the solver, which was defined automatically by the solver based on the calculated length and velocity scales. The calculated time-scale is then multiplied by a time-scale factor with a value of one as the CFX default option. But, for the CFD simulations with separated flow regions and openings with simultaneous inlet and outlets, lower values of time-scale factors should be applied. As this is a case for the cross-ventilation in sheltering conditions, a time-scale factor of 0.1 was considered. Higher values of time-scale factor resulted in solution divergence issues and fluctuations in the flow parameters, specifically for the structured hexahedral mesh (Mesh B).

\section{Results and discussion}

\subsection{Effect of mesh setting}

In Figure 4, vertical profiles of the streamwise velocity over lines B, C, F, I and J are shown for Mesh $\mathrm{A}$ and Mesh $\mathrm{B}$ against the wind angle of $\alpha=0^{\circ}$. The standard $k-\varepsilon$ model was used for the CFD calculations while the HR scheme and Tri-linear formulation were utilized for discretization of the advection and diffusion terms. The calculated velocity profiles by Mesh $A$, which has unstructured tetrahedral mesh configuration with a significant lower cell numbers than Mesh B (see Figure 3 and Table 2), are very similar to Mesh B which has a structured hexahedral mesh configuration with about 4.8 times larger computational cell numbers. The prediction values by Mesh A and Mesh B for the velocity field, wind surface pressure, and crossing airflow rate for oblique wind angles are not shown, but they are very close to each other. For instance, the total wind pressure difference estimated by Mesh $\mathrm{A}$ and Mesh $\mathrm{B}$ were $\Delta C_{P}^{\text {total }}=0.385$ and $\Delta C_{P}^{\text {total }}=$ 0.369 , respectively against the wind angle of $30^{\circ}$. In this case, the crossing airflow rate calculated by Mesh $A$ and Mesh B were respectively $\frac{q}{A_{o} U_{H}}=0.217$ and $\frac{q}{A_{o} U_{H}}=0.221$. 

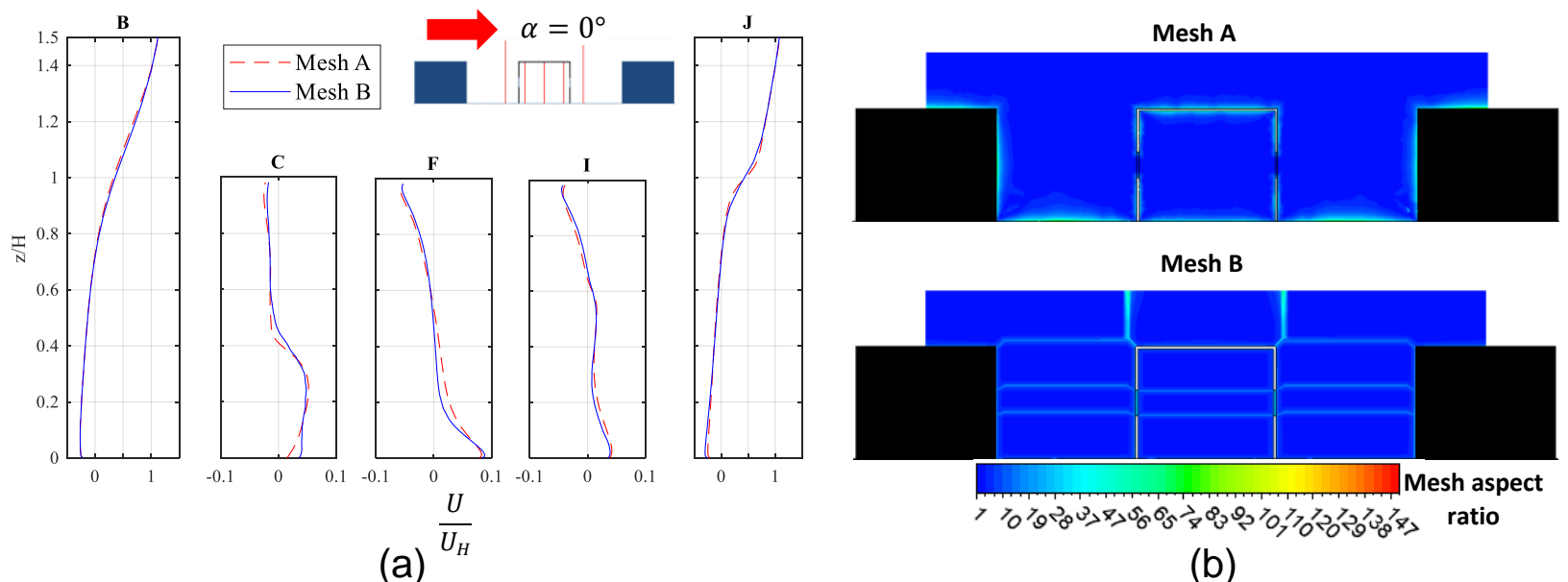

(b)

Figure 4 (a) Vertical profiles of the streamwise velocity for Mesh A and Mesh B against the wind angles of $0^{\circ}$. (b) Contours of mesh aspect ratio for Mesh A and Mesh B.

Mesh $\mathrm{B}$ does not only require considerable larger computational resources than Mesh $\mathrm{A}$, but also it has a very challenging to reach convergence with a significantly longer computational time against the normal wind angle. In addition to the observed fluctuations in the residuals of Mesh $\mathrm{B}$, there were fluctuations in the value of the streamwise velocity at three monitoring point placed inside and around the cross-ventilated building. Hence, the converged solution was obtained after more iterations than Mesh A. The convergence difficulty of Mesh B, observed against the wind angle of $0^{\circ}$, was not generally occurred for the oblique wind angles. Nevertheless, the run time of Mesh B was significantly high as explained before.

In order to investigate the poor convergence of Mesh B against the normal wind angle, mesh quality parameters of both mesh settings are compared. The orthogonality angle of Mesh $A$ and $B$ are respectively in the range of $63 \leq \theta \leq 170$ and $90 \leq \theta \leq 160$, which are in the acceptable range for the CFX solver. The mesh expansion factor of both mesh settings is in the acceptable range with values lower than 20 . In contrast, the mesh aspect ratio in some areas of the computational domain of both mesh settings is higher than the maximum acceptable value of 100 for the CFX solver. Contours of the mesh aspect ratio are displayed in Figure 4(b). The mesh aspect ratio of Mesh A is high only near the solid walls in the boundary layer mesh. In contrast, for Mesh B, high values of mesh aspect ratio are not limited only to the boundary layer region around solid walls, but also, they can be found inside the cross-ventilated building, upstream and downstream cavities around buildings, and even in the free stream region above buildings. This is due to the stretching of boundary layer mesh, which happens when the blocking technique is used for the structured hexahedral mesh generation for Mesh B. Existence of such high mesh aspect ratio regions inside the computational domain results in round-off error and affects the CFD solver convergence (CFX, 2011). Considering a lower cell numbers of Mesh A in comparison with Mesh $B$ also in addition to its better convergence performance, Mesh A was considered for all the simulations presented in the rest of the paper.

\subsection{Effect of discretization scheme}

\subsubsection{Velocity field}


Vertical profiles of the streamwise velocity $\left(\frac{U}{U_{H}}\right)$ along Lines $\mathrm{B}$ and $\mathrm{J}$ outside the building and along Lines $\mathrm{C}, \mathrm{F}$ and $\mathrm{I}$ inside the cross-ventilated building are plotted in Figure 5 against different wind angles for Mesh A using the UP and HR advection schemes. The standard $k-\varepsilon$ model was used in all simulations while Tri-linear formulation was selected for the diffusion term discretization.

It can be seen that the prediction accuracy of CFD model using UP and HR schemes are very close over Lines $B$ and $\mathrm{J}$ outside the building and it is higher than the obtained accuracy inside the building. In contrast, the sensitivity of CFD results to the advection scheme is significantly high in prediction of the velocity filed inside the cross-ventilated building over Lines $\mathrm{C}, \mathrm{F}$, and I.

Accuracy of the UP scheme is noticeably higher than the HR scheme over Lines $C$ and F against the wind angle of $\alpha=0^{\circ}$, as shown in Figure 5(a). Both the UP and HR schemes underestimate the $\frac{U}{U_{H}}$ over Lines I near the leeward façade. The prediction accuracy of the UP and HP schemes against the wind angle of $\alpha=30^{\circ}$ over Lines $\mathrm{B}, \mathrm{C}, \mathrm{I}$, and $\mathrm{J}$ are generally close to each other and are acceptable in comparison with the experimental data. Significant deviation is observed at the center of the building over Line $\mathrm{F}$ where the velocity and its gradients are very low.

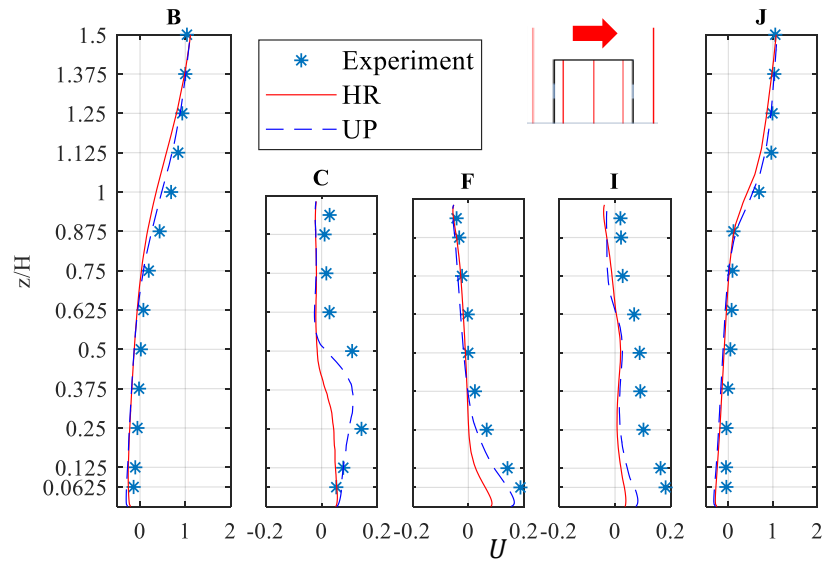

(a) $\overline{U_{H}}$

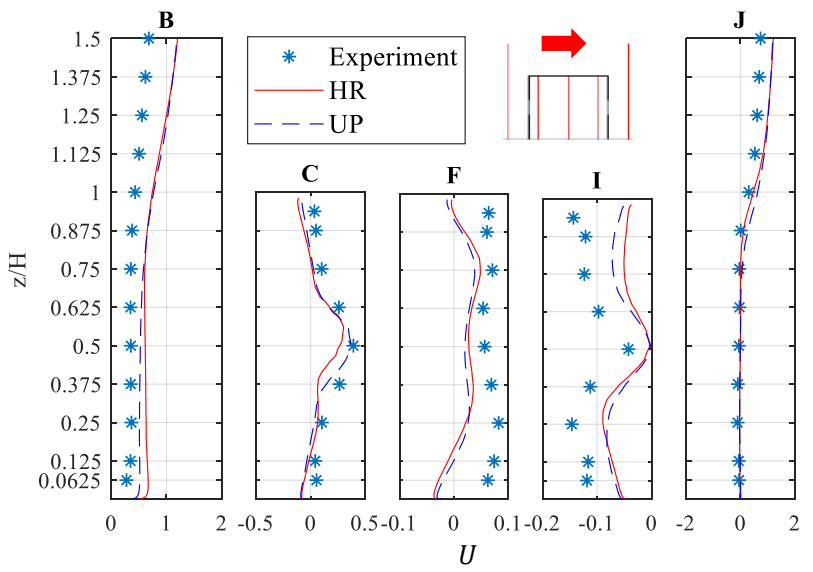

(c) $\frac{U}{U_{H}}$
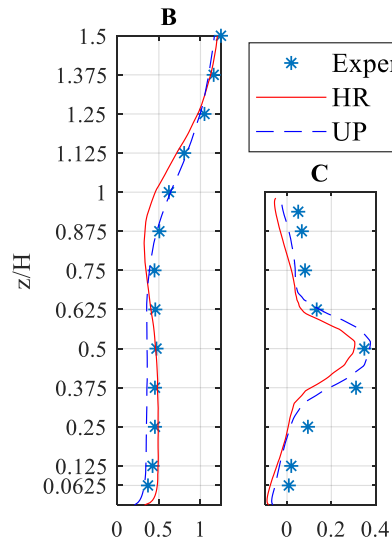

$\begin{array}{lll}0 & 0.2 & 0.4\end{array}$

${ }^{0} U^{0 .}$

(b) $\overline{U_{H}}$
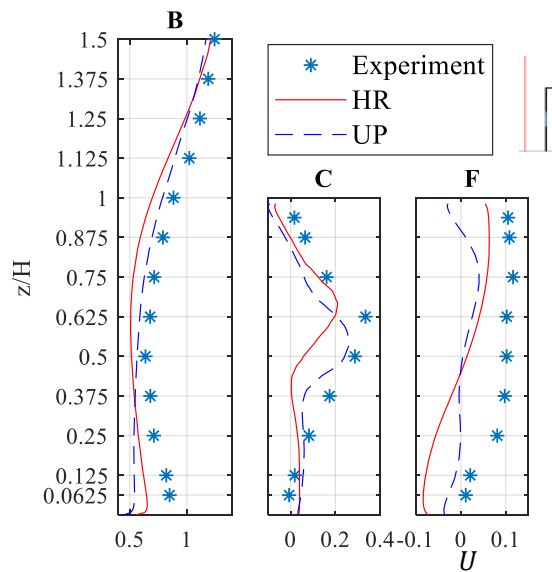

(d) $\frac{U}{U_{H}}$
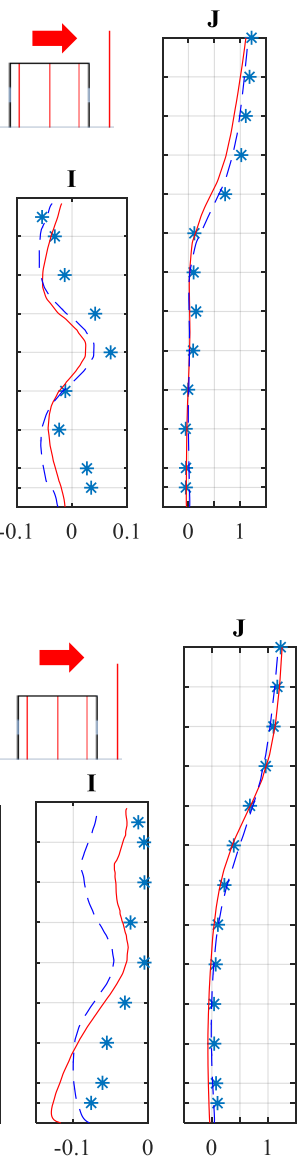

Figure 5 Vertical profiles of the streamwise velocity against the wind angle of (a) $\alpha=0^{\circ}$, (b) $\alpha=30^{\circ}$, (c) $\alpha=45^{\circ}$, and (d) $\alpha=60^{\circ}$ for different advection discretization schemes 
The values of $\frac{U}{U_{H}}$ are over predicted by the UP and HR schemes over Lines $B$ and $\mathrm{J}$ against the wind angle of $\alpha=45^{\circ}$ specifically in the shear layer above the building roofs $\left(1 \leq \frac{Z}{H} \leq 1.5\right)$ while a close agreement between the CFD results are obtained along Lines $\mathrm{C}$ and $\mathrm{F}$. The deviation between the UP and HR scheme's results are very negligible against this wind angle. In contrast, against the wind angle of $\alpha=60^{\circ}$, a significant deviation between the predicted values by the HR and UP schemes are observed over all lines excluding Line $\mathrm{J}$ in the downstream cavity.

In Figure 6, the vertical distribution of TKE along Lines B, C, F, I, and J are shown against different wind angles using the UP and HR advection schemes. Accuracy of the UP and HR schemes in prediction of the TKE distribution is considerably lower than their accuracy in prediction of the time-averaged velocity field (see Figure 5). Against the normal wind angle, as shown in Figure 6(a), the UP scheme shows a better agreement with the experimental values in comparison with the HR scheme over Lines $B$ and $J$ outside the cross-ventilated building. Inside the building, over Lines C, F, and I, both models noticeably underestimate the TKE level even around the windward jet where the TKE level is high.

When the wind angle rises to $\alpha=30^{\circ}$, the experimental value of TKE distribution does not change significantly over Lines $B$ and $J$ in the windward and leeward cavities. The HR scheme shows a better agreement in comparison with the UP scheme specifically over Line B. While the TKE level inside the building shows an increase in comparison with the case of normal wind angle, the accuracy of the HR scheme is found to be higher than the UP scheme over Lines C, F, and I. Nevertheless, both models underestimate the TKE level. The same trend is observed when the wind angle increases to $\alpha=45^{\circ}$, where the HR scheme shows a better agreement with the experimental results. In this case, both models captured the trend of the TKE variation along Lines $B, F$, and I inside the building, while the UP scheme underestimates the TKE level specifically over Line $\mathrm{B}$ around the windward jet. Against the wind angle of $\alpha=60^{\circ}$, the deviation between the UP and HR schemes' predictions is very considerable along Line B in the windward cavity while very close results are obtained over Line $\mathrm{J}$ in the leeward cavity. 


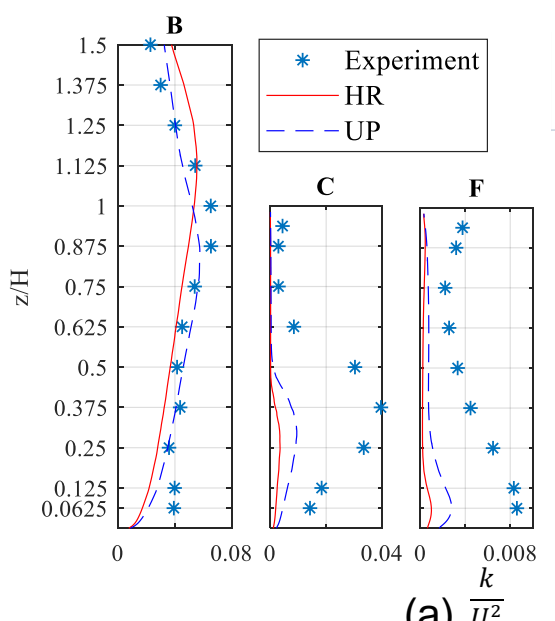

(a) $\frac{k}{U_{H}^{2}}$

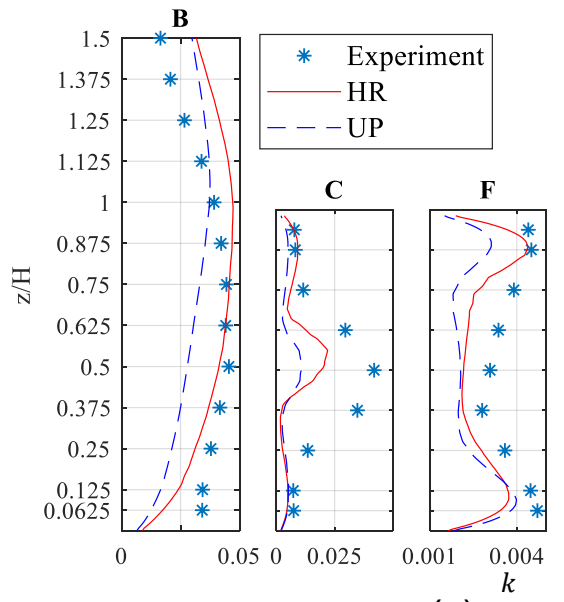

(c) $\frac{k}{U_{H}^{2}}$
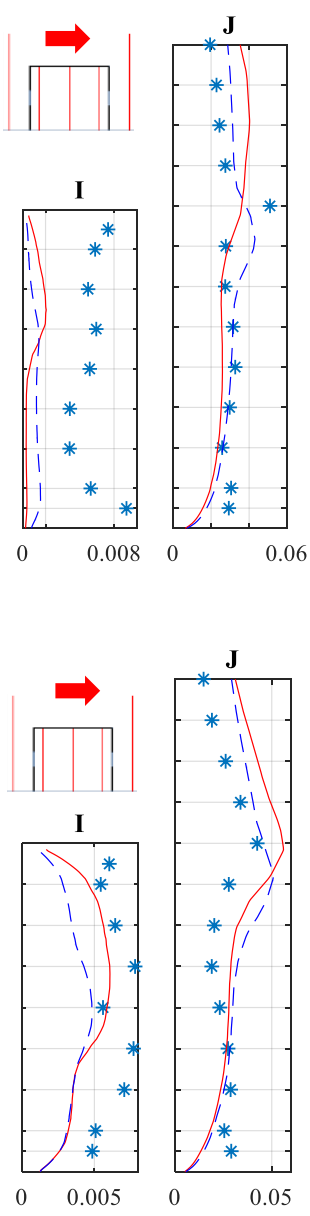
distribution against the wind angle of (a) $\alpha=0^{\circ}$, (b)
$60^{\circ}$ for different advection discretization schemes
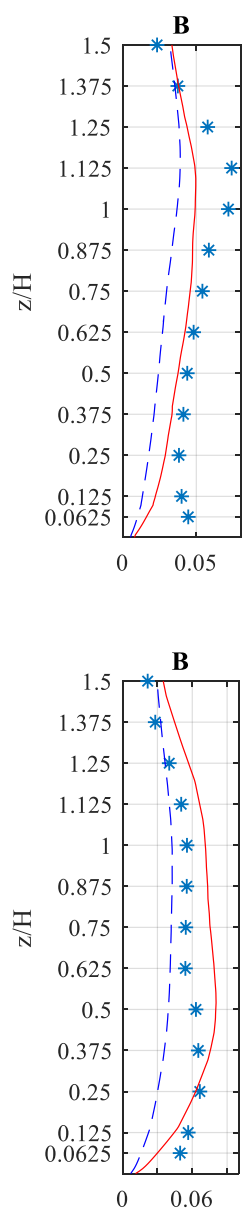
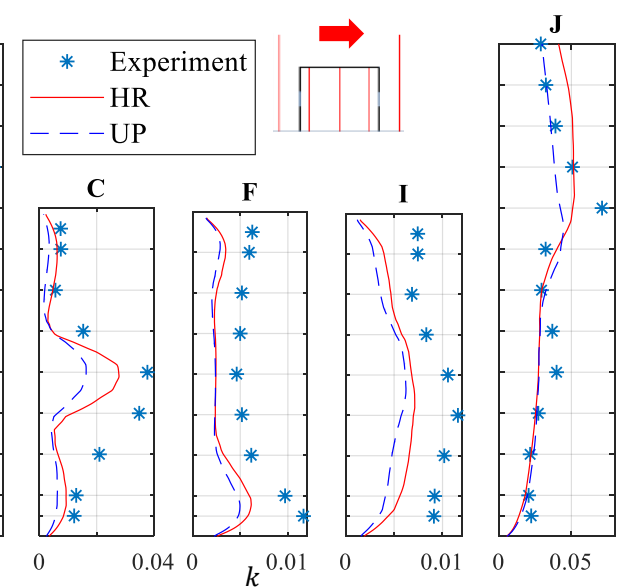

(b) $\overline{U_{H}^{2}}$
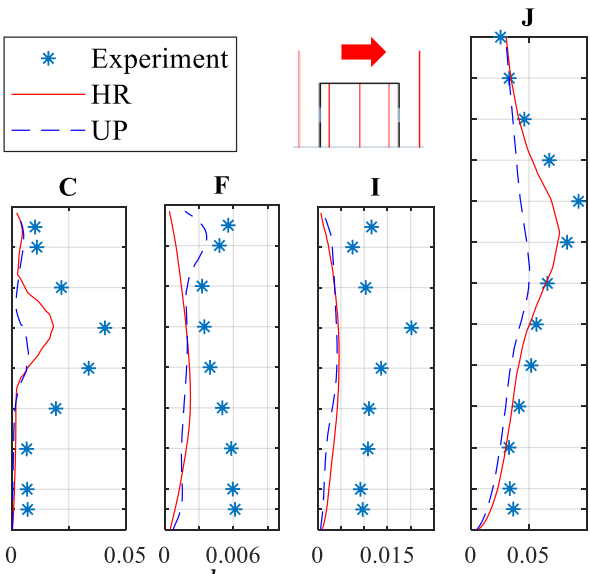

(d) $\frac{k}{U_{H}^{2}}$

Figure 6 Vertical profiles of the TKE distribution against the wind angle of (a) $\alpha=0^{\circ}$, (b) $\alpha=30^{\circ}$, (c) $\alpha=45^{\circ}$, and (d) $\alpha=$

Contours of the velocity magnitude $\left(\frac{\text { Velocity }}{U_{H}}\right)$ and TKE $\left(\frac{k}{U_{H}^{2}}\right)$ over a horizontal plane at the height of $\frac{Z}{H}=0.5$ are depicted in Figure 7 for the UP and HR schemes against different wind angles. Considering the velocity distribution, in general, the UP scheme predicts a shorter wake region behind the buildings against all wind angles. In specific, against the wind angle of $\alpha=0^{\circ}$, the time-averaged velocity predictions by the UP scheme are higher than the HR scheme over the horizontal plane in the windward and leeward cavities, which consequently results in a higher windward jet velocity by the UP scheme (see Figure 5(a)). Against the oblique wind angles, the channeling effect of the adjacent buildings is clearly observed where a high velocity level is calculated near the windward jet, resulting in much higher CFD prediction accuracy of the windward jet in comparison with the normal wind condition (see Figure 5(b), (c), and (d)). In contrast, the TKE level calculated by the UP scheme is lower than the one predicted by the HR scheme over the horizontal plane against all wind angles. It can be seen that the changed TKE distribution pattern against oblique wind angles in the wake region of the upstream building over the horizontal plane is followed by a higher TKE level inside the cross-ventilated building. As a result, better agreements with the experimental measurement can be obtained in comparison with the case with the normal wind angle by the UP and HR schemes. 

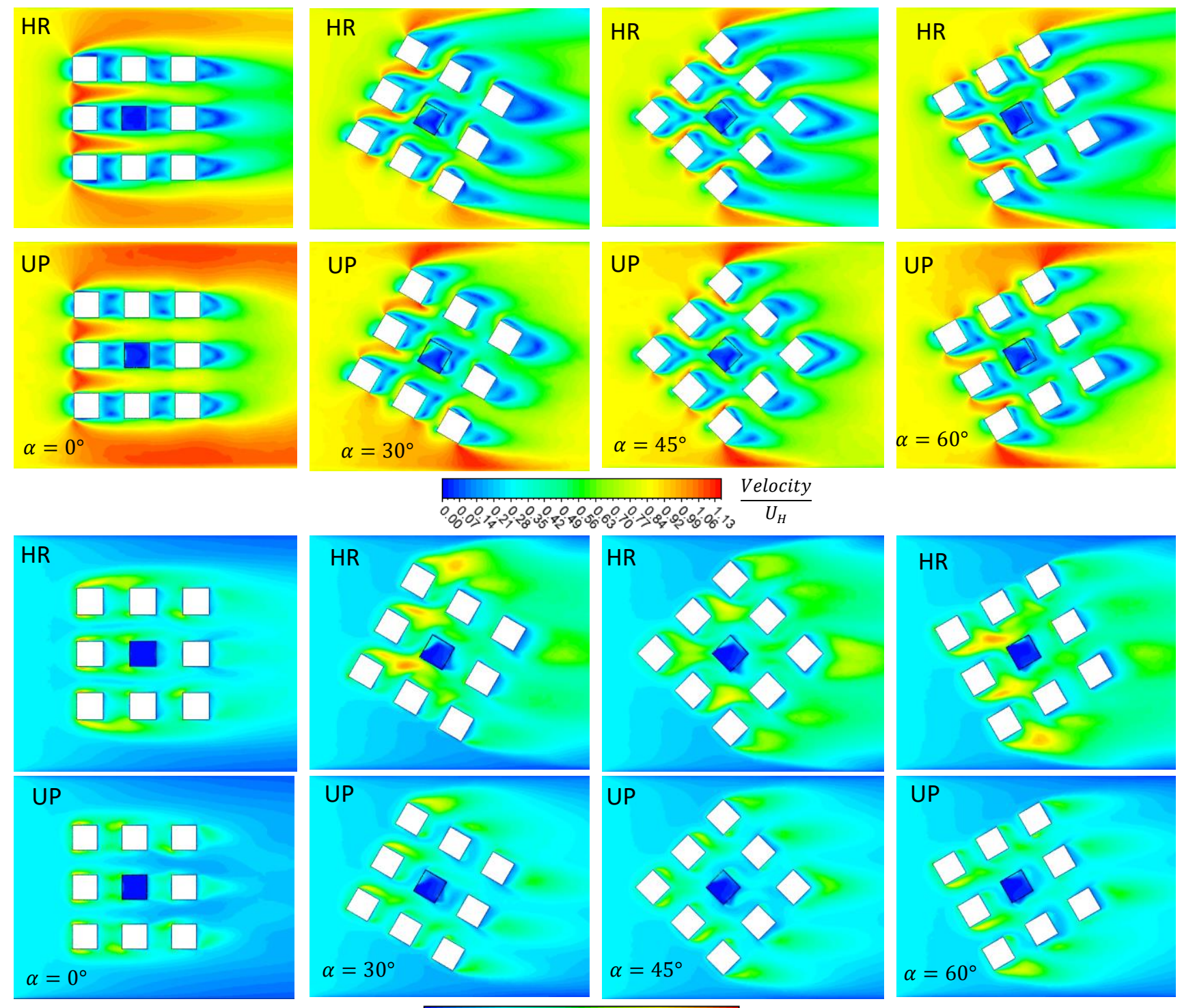

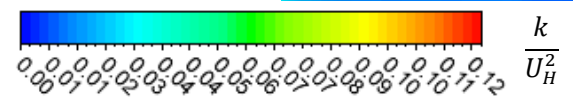

Figure 7 Contours of the time-averaged velocity and TKE over a horizontal plane at $\frac{Z}{H}=0.5$ for different advection discretization schemes

As shown in Table 3, the validation metrics (Tominaga, 2015) for the time-averaged velocity components and TKE are calculated over all 115 measurement points (see Figure 2(a)) for the HR and UP schemes against different wind angles. Against the normal wind angle $\left(\alpha=0^{\circ}\right)$, the prediction accuracy of the UP scheme is higher than the HR scheme. The calculated values of $q_{u}, q_{w}, F A C 2_{u}, F A C 2_{w}, q_{k}, F A C 2_{k}, F B_{k}$, and $N M S E_{k}$ are respectively $0.27,0.73,0.36,0.57,0.47$, $0.45,0.18$, and 0.21 for the UP scheme while they are respectively $0.25,0.68,0.27,0.32,0.32$, $0.44,0.26$, and 0.33 for the HR scheme. Despite these low differences between the validation metrics calculated for the UP and HR schemes, the predicted velocity field by two models are very different as shown in Figure 5(a) where no windward jet is predicted by the HR scheme. Against the wind angles of $\alpha=30^{\circ}$ and $\alpha=45^{\circ}$, as shown in Figure 5(b) and 5(c), both models predict important features of the flow field (e.g., windward and leeward jets), while the accuracy 
of the HR scheme in prediction of the time-averaged velocity components is slightly higher than the UP scheme. The prediction accuracy of the HR scheme in prediction of the TKE distribution is considerably higher than the UP scheme against these two wind angles. For instance, against the wind angle of $\alpha=30^{\circ}$, the values of $q_{k}, F A C 2_{k}, F B_{k}$, and $N M S E_{k}$ are respectively $0.29,0.54$, 0.45 , and 0.49 for the UP scheme while they are $0.51,0.76,0.18$, and 0.16 , respectively for the $\mathrm{HR}$ scheme. The same trend is observed against the wind angle of $\alpha=60^{\circ}$ where the TKE prediction accuracy of the HR scheme is significantly higher than the UP scheme. Nevertheless, the prediction accuracy of the UP scheme is slightly higher than the HR scheme in terms of validation metrics for the time-averaged velocity while both models provide generally a good picture of the time-averaged flow field as shown in Figure 5(d).

Table 3 Validation metrics for the streamwise velocity $(U)$, lateral velocity $(V)$, and vertical velocity $(W)$, and TKE $(k)$
\begin{tabular}{|c|c|c|c|c|c|c|c|c|c|c|c|}
\hline Discretization scheme & $q_{U}$ & $q_{v}$ & $q_{W}$ & $F A C 2_{U}$ & $F A C 2_{v}$ & $F A C 2_{W}$ & $q_{k}$ & $F A C 2_{k}$ & $F B_{k}$ & $N M S E_{k}$ \\
\hline \multirow{2}{*}{$\alpha=0^{\circ}$} & $\mathrm{UP}$ & 0.27 & $*$ & 0.73 & 0.36 & $*$ & 0.57 & 0.47 & 0.45 & 0.18 & 0.21 \\
\cline { 2 - 14 } & $\mathrm{HR}$ & 0.25 & $*$ & 0.68 & 0.27 & $*$ & 0.32 & 0.32 & 0.44 & 0.26 & 0.33 \\
\hline \multirow{3}{*}{$\alpha=30^{\circ}$} & $\mathrm{UP}$ & 0.37 & 0.12 & 0.48 & 0.45 & 0.37 & 0.24 & 0.29 & 0.54 & 0.45 & 0.49 \\
\cline { 2 - 13 } & $\mathrm{HR}$ & 0.30 & 0.13 & 0.50 & 0.41 & 0.35 & 0.26 & 0.51 & 0.76 & 0.18 & 0.16 \\
\hline \multirow{2}{*}{$\alpha=45^{\circ}$} & $\mathrm{UP}$ & 0.11 & 0.43 & 0.71 & 0.42 & 0.51 & 0.41 & 0.59 & 0.82 & 0.18 & 0.52 \\
\cline { 2 - 13 } & $\mathrm{HR}$ & 0.17 & 0.42 & 0.62 & 0.44 & 0.43 & 0.56 & 0.64 & 0.88 & -0.03 & 0.28 \\
\hline \multirow{2}{*}{$\alpha=60^{\circ}$} & $\mathrm{UP}$ & 0.40 & 0.20 & 0.25 & 0.50 & 0.38 & 0.16 & 0.19 & 0.43 & 0.54 & 0.66 \\
\cline { 2 - 12 } & $\mathrm{HR}$ & 0.36 & 0.11 & 0.19 & 0.55 & 0.25 & 0.17 & 0.37 & 0.46 & 0.15 & 0.19 \\
\hline
\end{tabular}

\subsubsection{Wind surface pressure}

Variation of the total pressure difference coefficient $\left(\Delta C_{P}^{\text {total }}\right)$ against different wind angles is plotted in Figure 8 for the UP and HR schemes while the standard $k-\varepsilon$ model is used as the turbulence model. The prediction values of the $\Delta C_{P}^{\text {total }}$ by the HR scheme are in generally in a closer agreement with the experimental results against all oblique wind angles while the UP scheme significantly over-predict the surface pressure difference coefficient. The experimentally measured values of $\Delta C_{P}^{\text {total }}$ are $0.35,0.32$, and 0.16 , against the wind angles of $30^{\circ}, 45^{\circ}$, and $60^{\circ}$, respectively. These values are $0.38,0.34$, and 0.22 for the $\mathrm{HR}$ scheme and $0.48,0.41$, and 0.29 for the UP scheme against the wind angles of $30^{\circ}, 45^{\circ}$, and $60^{\circ}$, respectively. In contrast, the UP scheme prediction against the normal wind angle $\Delta C_{P}^{\text {total }}=0.18$ is very close to the experimental value, i.e., $\Delta C_{P}^{\text {total }}=0.17$, while the $\mathrm{HR}$ scheme noticeably underestimates the pressure difference with a value of $\Delta C_{P}^{\text {total }}=0.02$.

\subsubsection{Crossing airflow rate}

The same trend is observed for the crossing airflow rate $\left(\frac{q}{A_{o} U_{H}}\right)$ through the building openings as it was observed for the surface pressure difference coefficients. The HR scheme predictions are closer to the experimental values against all oblique wind angles while the UP scheme predictions are slightly far from the experimental values. While the experimental values of the $\frac{q}{A_{o} U_{H}}$ are 0.16 , 0.13 , and 0.11 against the wind angles of $30^{\circ}, 45^{\circ}$, and $60^{\circ}$, respectively, the prediction values by 
the HR and UP schemes are respectively $0.22,0.19,0.12$, and $0.24,0.2,0.15$. In contrary, against the normal wind angle, the HR scheme prediction of the crossing airflow rate is very inaccurate with a value of $\frac{q}{A_{o} U_{H}}=0.01$. The UP scheme prediction of the crossing airflow rate is $\frac{q}{A_{o} U_{H}}=0.08$, which is closer to the experimental value of $\frac{q}{A_{o} U_{H}}=0.12$.

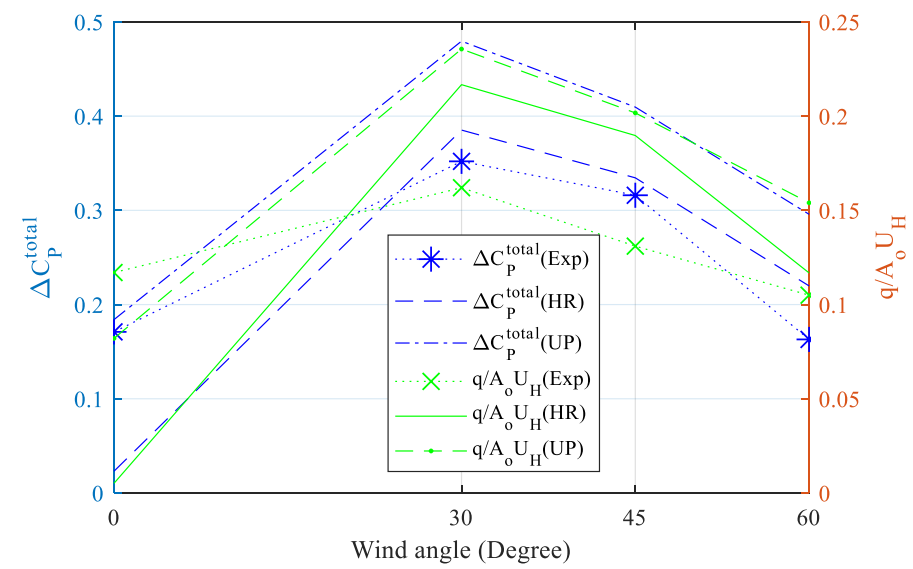

Figure 8 Variation of the total pressure difference coefficient $\left(\Delta C_{P}^{\text {total }}\right)$ and airflow rate $\left(\frac{q}{A_{o} U_{H}}\right)$ against different wind angles

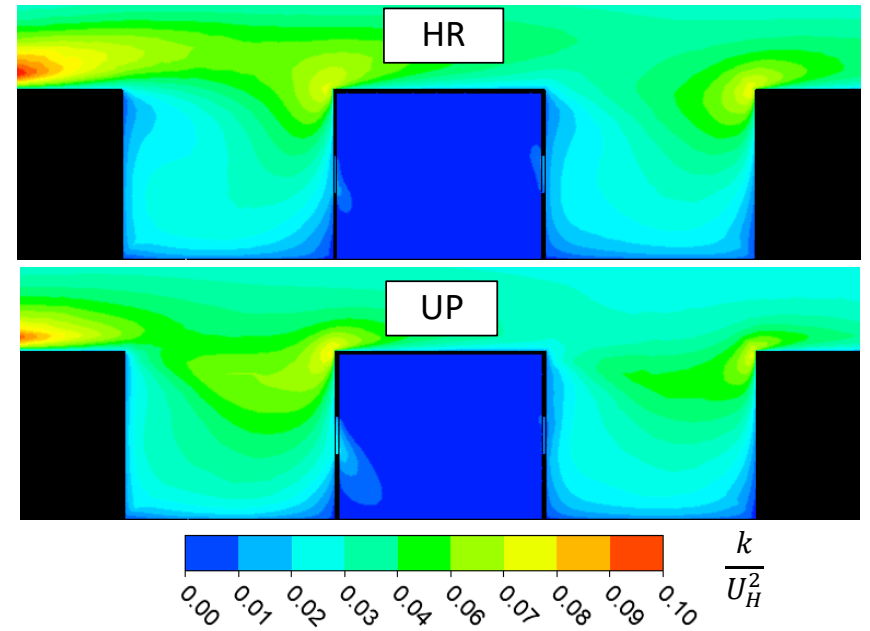

Figure 9 Distribution of the TKE inside the windward and leeward cavities againd the wind angle of $0^{\circ}$

Comparison of the time-averaged velocity components, TKE, wind surface pressure coefficient, and crossing airflow rate calculated by the HR and UP discretization schemes reveals that the accuracy of the HR scheme is generally higher than the UP scheme with an only exception against the normal wind angle. In the case of normal wind angle, the velocity in the windward and leeward cavities are very low in comparison with oblique wind angle conditions due to the obstruction effect of the surrounding buildings. In this case, the well-known underestimation of the momentum diffusion by the steady RANS solvers clearly affects the flow field prediction. As shown in Figure 9, when the HR discretization scheme is used against the wind angle of $0^{\circ}$, the TKE level inside the windward and leeward cavities are found to be very low, but when the UP scheme is utilized, the TKE distribution shows significant increases. Since the contribution of the turbulence production is considerably high around the windward jet (Tominaga \& Blocken, 2015), larger velocity gradient and hence a more accurate velocity field is predicted by the UP scheme. Hence, the numerical diffusion caused inherently by the UP scheme compensates the low momentum diffusion by the steady RANS model. In the case of other wind angles, as shown in Figure 5, Figure 6, and Figure 8, the discretization error of the UP scheme generally reduces the accuracy of CFD predictions of the velocity field, wind surface pressure, and crossing airflow rate.

\subsection{Effect of turbulence models}

Accuracy of three turbulence models, including the standard $k-\varepsilon$, RNG $k-\varepsilon$, and $k-\omega$ SST models is investigated in this section against different wind angles. Mesh $A$ is used for all simulations while the HR scheme is considered for discretization of the diffusion term in the momentum equation. 


\subsubsection{The velocity field}

In Figure 10, vertical distributions of the time-averaged streamwise velocity $\left(\frac{U}{U_{H}}\right)$ calculated by different turbulence models are depicted against different wind angles. The accuracy of all turbulence models in prediction of the $\frac{U}{U_{H}}$ distribution outside the building over Lines $\mathrm{B}$ and $\mathrm{J}$ are significantly higher than the velocity distribution over Lines C, F, and J. Against the normal wind angle, all turbulence models fail to accurately predict the velocity filed inside the building. The accuracy of all models improves when the wind angle increases to $\alpha=30^{\circ}$ where the windward and leeward jets are predicted quite accurately. The RNG $k-\varepsilon$ and $k-\omega$ SST models calculate the location of the velocity peak near the windward opening at a lower height comparing to the experiment. The same trend is observed against the wind angle of $\alpha=45^{\circ}$ where the $k-\omega$ SST model underestimates the location of the velocity peak over Line C. In this case, a noticeable deviation between the CFD and experimental results is observed over Lines B and $\mathrm{J}$ not only inside the cavity, but also in the shear layer above the building roof. When the wind angle rises to $\alpha=60^{\circ}$, all turbulence models overestimate the location of velocity peak over Line B near the windward opening while their prediction accuracy are very close to each other over Lines $F$ and I. 

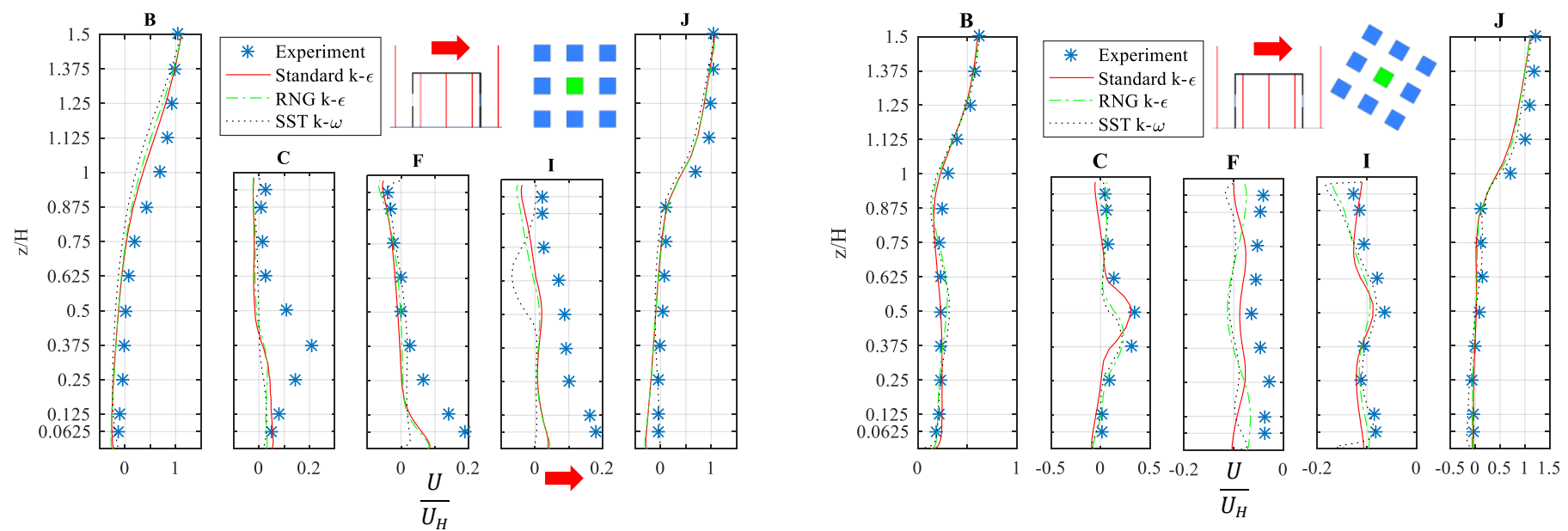

(a) $\boldsymbol{\alpha}=\mathbf{0}^{\circ}$

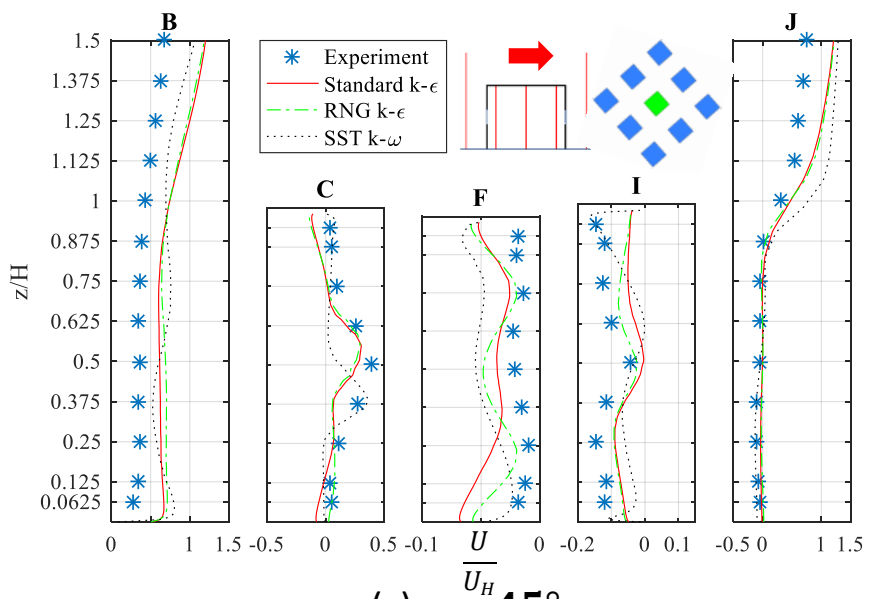

(c) $\boldsymbol{\alpha}={ }^{U_{H}} \mathbf{4 5}^{\circ}$

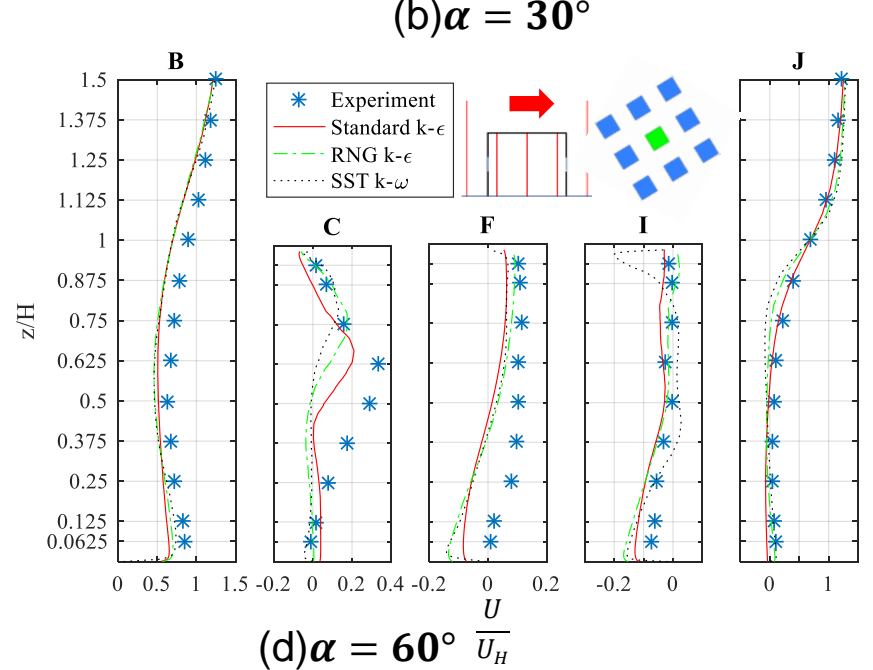

Figure 10 Vertical profiles of the streamwise velocity calculated by different turbulence models against different wind angles

In Figure 11, the vertical distribution of TKE calculated by different wind angles are shown over Lines B, C, F, I, and F against different wind angles. In general, the accuracy of all turbulence models in prediction of TKE distribution outside the building is higher than those inside the building. Against the normal wind angle, the standard $k-\varepsilon$ model shows more agreement with the experimental results over Lines B and J outside the building while the RNG $k-\varepsilon$ and $k-\omega$ SST models slightly underestimate the TKE values. Near leeward opening and over Line I, all models underestimate the TKE level. When the wind angle rises to $\alpha=30^{\circ}$, the prediction accuracy of all turbulence models shows a significant improvement. Over Lines B and $\mathrm{J}$, the standard $k-\varepsilon$, RNG $k-\varepsilon, k-\omega$ SST models predict similar results while the standard model more accurately calculates the TKE build up near the windward jet inside the building. The same trends are observed against the wind angles of $\alpha=45^{\circ}$ and $\alpha=60^{\circ}$. In these cases, the $k-\omega$ SST model shows a very low accuracy relative to the other turbulence models.

It can be seen that for oblique wind angle conditions, the RANS models accuracy in prediction of the TKE inside the building shows a significant improvement in comparison with the normal wind 
angle. This is due to the increased velocity gradient inside the building in the case of the oblique wind angle, which is accompanied by an increased contribution of the TKE production.
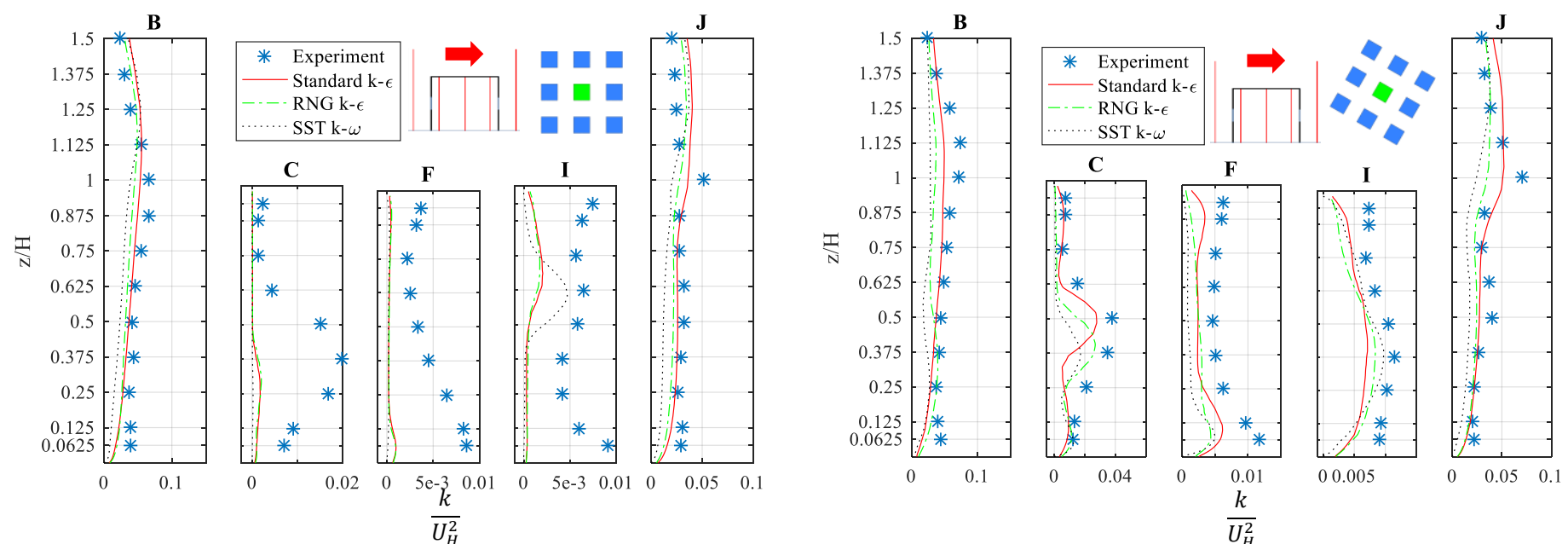

(a) $\alpha=0^{\circ}$
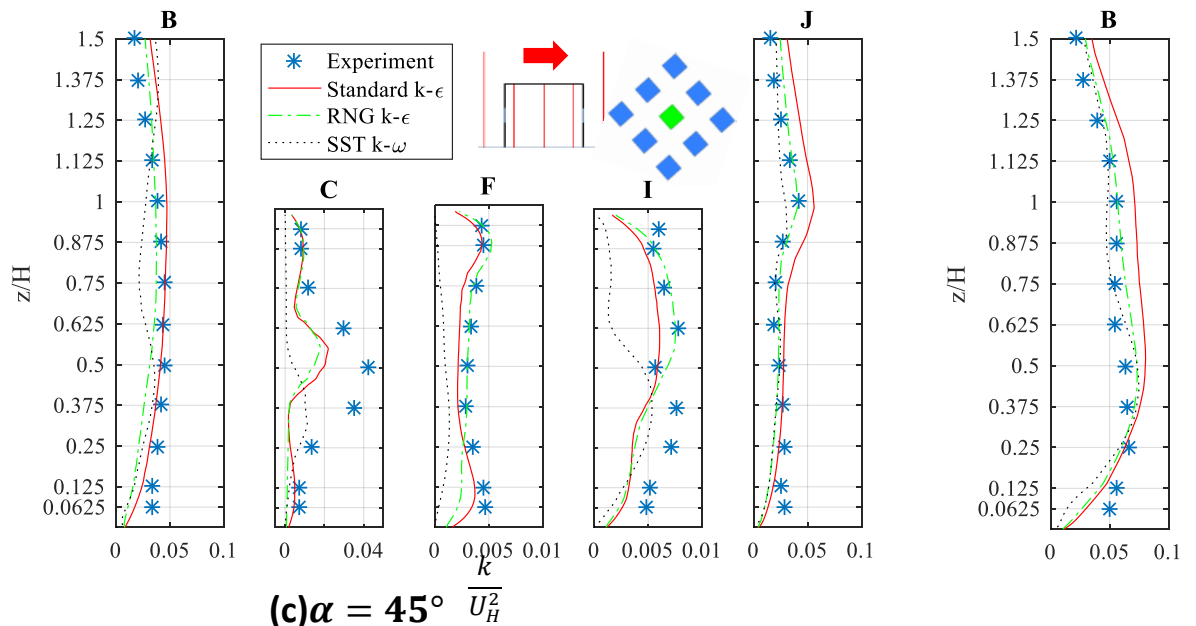

(b) $\alpha=30^{\circ} \frac{k}{U_{H}^{2}}$
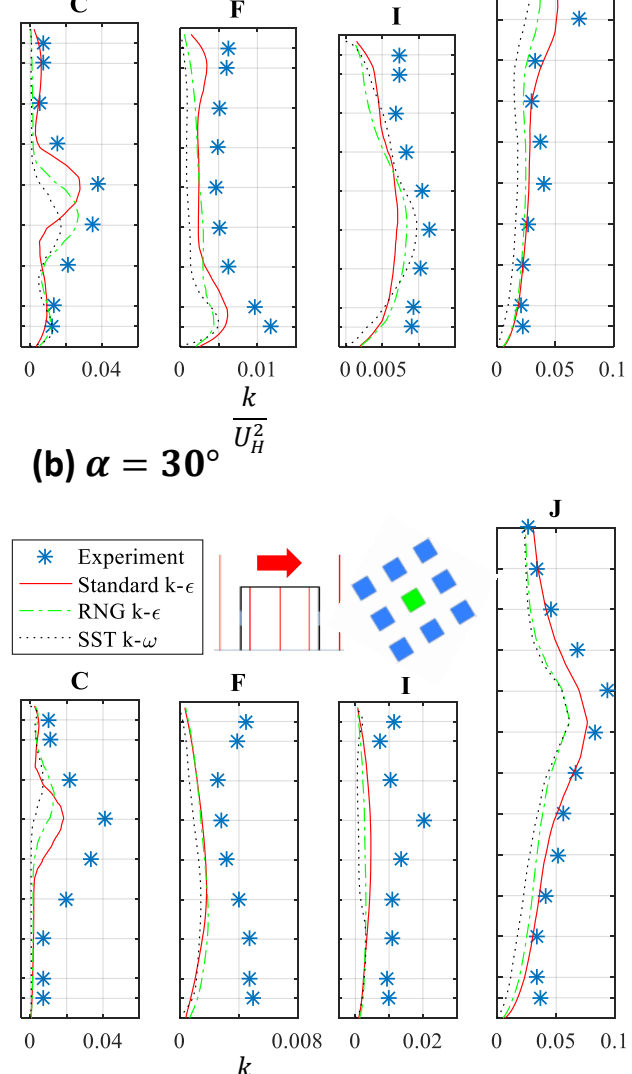

(d) $\boldsymbol{\alpha}=60^{\circ} \frac{k}{U_{H}^{2}}$

Figure 11 Vertical profiles of the TKE calculated by different turbulence models for Mesh A against different wind angles at the planar area ratio of $\lambda_{P}=0.25$

Distributions of the 3D streamlines inside the building calculated by different turbulence models are shown in Figure 12 against different wind angles. Furthermore, the mean of the time-averaged airflow directions over the windward and leeward openings are shown in this figure as the windward and leeward jet angles $\left(\beta_{W W}, \beta_{L W}\right)$. In the case of the normal wind angle, the velocity magnitude over the horizontal plane is very low and hence the streamlines are plotted over a vertical plane. The experimental measurement of the same case shows a large recirculating flow over the vertical plane while the center of the circulation is close to the leeward opening (see (M. Shirzadi, Mirzaei, Naghashzadegan, et al., 2018; Mohammadreza Shirzadi, Tominaga, \& Mirzaei, 2019). Different patterns are predicted by different turbulence models. The predicted windward jet angles $\left(\beta_{W W}\right)$ by the standard $k-\varepsilon$, RNG $k-\varepsilon, k-\omega$ SST models are $-89.15^{\circ},-86.8^{\circ}$, and $-80^{\circ}$, respectively. The airflow leaves the building with an upward orientation with leeward jet 
angles $\left(\beta_{L W}\right)$ of $89.7^{\circ}$ and $86^{\circ}$ calculated by the standard $k-\varepsilon$ and RNG $k-\varepsilon$ models, respectively. The $k-\omega$ SST model shows a different wind angle of about $\beta_{L W}=150^{\circ}$, which wrongly indicates that the airflow enters the building through the leeward opening.

For the oblique wind angles, it can be seen that the velocity pattern inside the building is very complex with a highly 3D distribution, specifically in the areas far from the openings. The average windward $\left(\beta_{W W}\right)$ and leeward $\left(\beta_{L W}\right)$ jet angles projected over the horizontal plane are calculated and shown for each case. Different windward and leeward jet angles are predicted by different turbulence models, but the deviation between the results is lower than the case with the normal wind angle. Against the wind angle of $\alpha=30^{\circ}$, the windward jet predicted by the standard $k-\varepsilon$, RNG $k-\varepsilon$, and $k-\omega$ SST are in the range of $34^{\circ} \leq \beta_{W W} \leq 38^{\circ}$. The leeward jet prediction by the standard $k-\varepsilon$ and $k-\omega$ SST models are very close in the range of $-65^{\circ} \leq \beta_{L W} \leq-63^{\circ}$, but the RNG $k-\varepsilon$ predicts different value about $\beta_{L W}=-73^{\circ}$. The standard $k-\varepsilon$ and RNG $k-\varepsilon$ models predict a large recirculating flow inside the building, which is similar to the flow visualization results discussed in (Mohammadreza Shirzadi, Tominaga, et al., 2019) while the flow field prediction by the $k-\omega$ SST model is completely incompatible.

When the wind angle rises to $\alpha=45^{\circ}$, the jet angles change due to the different flow pattern in the street canyon around the target building. The windward jet angle shows an increase in comparison to the case with the wind angle of $\alpha=30^{\circ}$, and reaches to a value of about $\beta_{W W}=$ $25^{\circ}$ for all turbulence models. The leeward jet angle increases significantly to values between $-88^{\circ} \leq \beta_{L W} \leq-83^{\circ}$. The 3D flow pattern is different for each turbulence model, but in general it features three circulating flow regions, which coincide each other and forma complex pattern.

Against the wind angle of $\alpha=60^{\circ}$, the airflow enters the target building with a very low windward jet angle of about $\beta_{W W}=16^{\circ}$, but it leaves with a high leeward jet angle, ranging from $\beta_{L W}=$ $-105^{\circ}$ by the standard $k-\varepsilon$ model and $\beta_{L W}=-118^{\circ}$ by the RNG $k-\varepsilon$ model. The predicted flow patterns by different turbulence models are generally similar and exhibiting multiple circulations inside the building. 


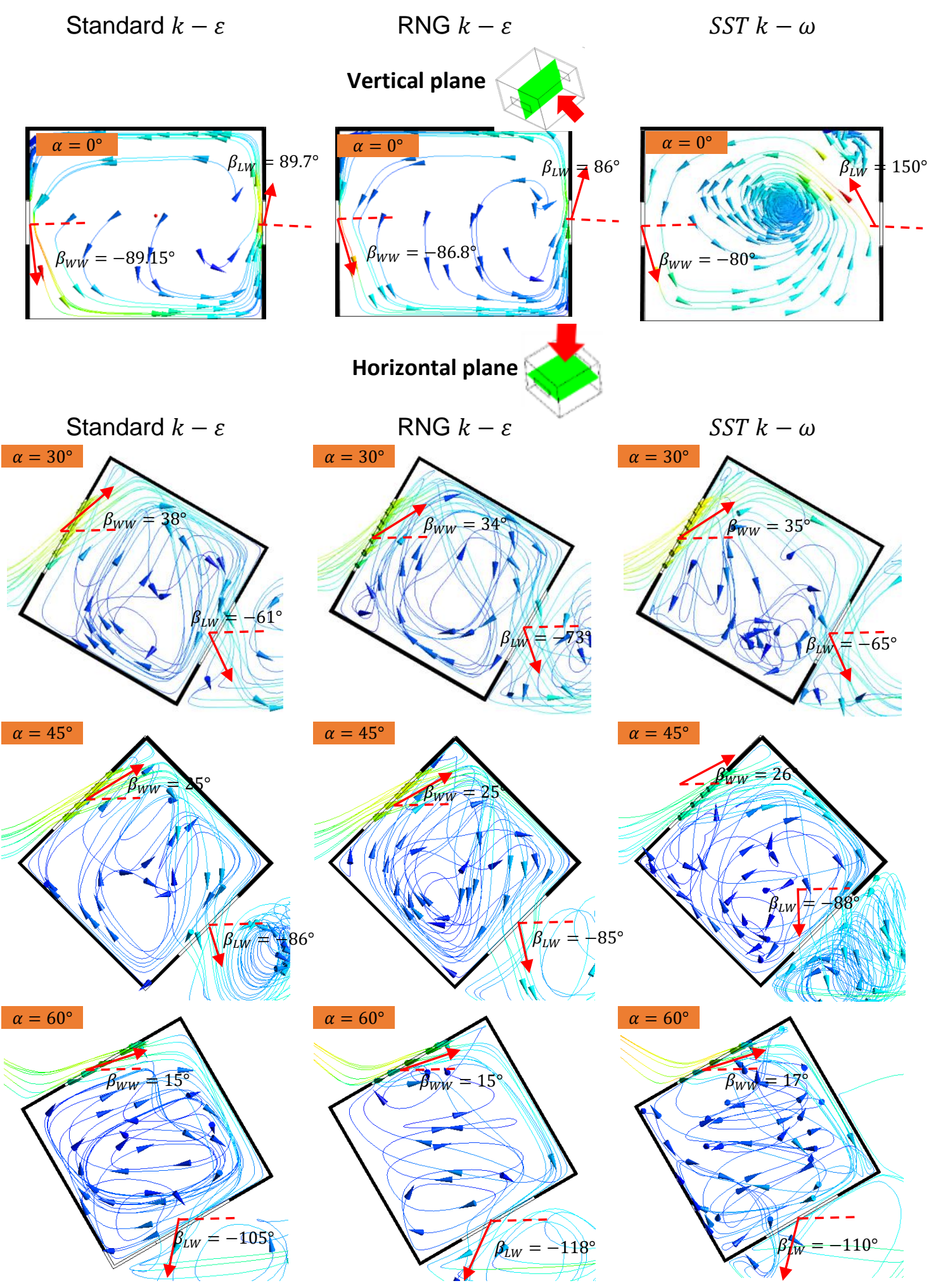

Figure 12 Distribution of the streamlines inside the building against different wind angles 
The accoracy of all turbulence models in prediction of the time-averaged velocity components and TKE are compared in terms of validation metrics as shown in Figure 13 against different wind angles. The ideal values of validation metrics are shown by dotted red lines. In general, CFD results for the time-averaged vertical velocity $(W)$ are more accurate than $U$ and $V$ components against all wind angles.

The accuracy of the standard $k-\varepsilon$ is the highest in prediction of the velocity and TKE fields against the nomal wind angle. Nevetheless, as shown previously, none of the turbulence models calculate the main flow features inside the builidng. Against the wind angle of $\alpha=30^{\circ}$, the RNG $k-\varepsilon$ model's accuracy shows the highest velocity prediction while the standard $k-\varepsilon$ model exhibits better results for TKE. Similar to the normal wind angle condition, the $k-\omega$ SST model's accuracy in prediction of TKE is very low, specifically in terms of $N M S E_{k}$ and $F B_{k}$. For the higher wind angles, i.e. $\alpha=45^{\circ}$ and $\alpha=60^{\circ}$, accuracy of the standard $k-\varepsilon$ and RNG $k-\varepsilon$ models are slightly higher than the $k-\omega \mathrm{SST}$ model in prediction of both velocity and TKE fields.

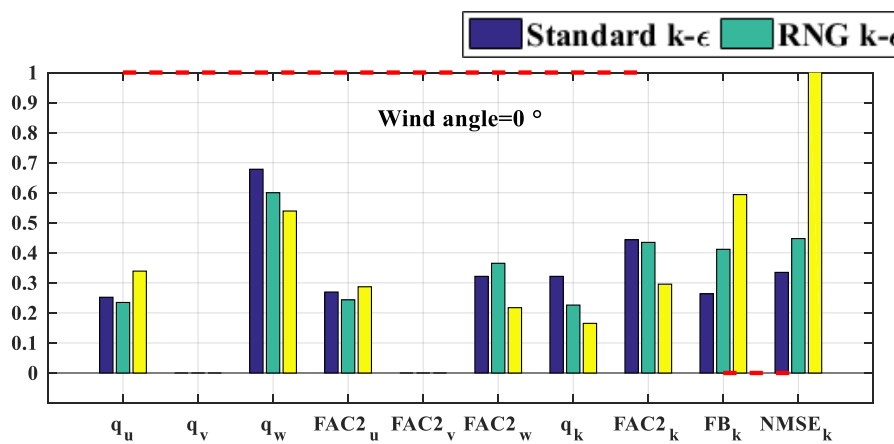

$\neg$ SST k- $\omega$ - - Ideal value
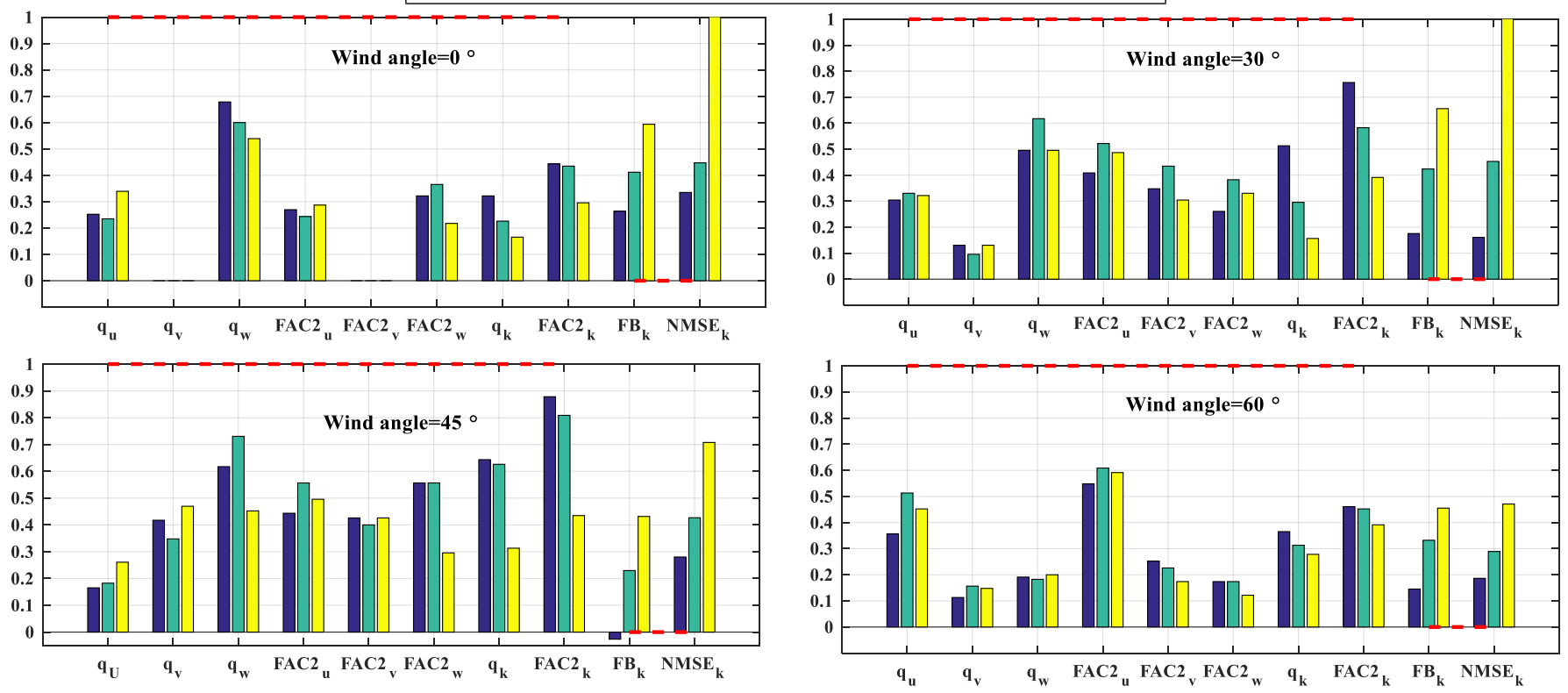

Figure 13 Validation metrics for the time-averaged velocity components and TKE over 115 measurement points against different wind angles calculated by different turbulence models

\subsubsection{The surface wind pressure}

Distributions of the surface wind pressure coefficient over the windward and leeward facades are plotted in Figure 14 for different turbulence models against different wind angles. Mesh A is used for CFD simulations using the HR scheme and Tri-linear formulation. Against the normal wind angle, the wind pressure coefficient distribution over the windward façade $\left(C_{P}^{w w}\right)$ is generally similar for all turbulence models while a high value is calculated near the roof height. Over the leeward façade, more uniform wind pressure coefficient $\left(C_{P}^{l w}\right)$ distributions are calculated while different patterns are predicted by each turbulence model.

Against the oblique wind angles, the $C_{P}^{w w}$ shows a peak near the corner of the windward façade while the height of the peak $C_{P}^{w w}$ area changes against different wind angles. Against the wind 
angle of $30^{\circ}$, the peak area is near the $2 / 3 H$ while ${ }^{\circ}$ the peak occurs around $1 / 3 H$ against the wind angle of 60 . In most of the cases, the $C_{P}^{w w}$ distributions are quite similar for all turbulence models. The observed differences between the wind pressure distributions are mainly due to the discrepancy in prediction of the velocity field in the street canyon by each turbulence model as shown in Figure 5, Figure 7, and Figure 10.

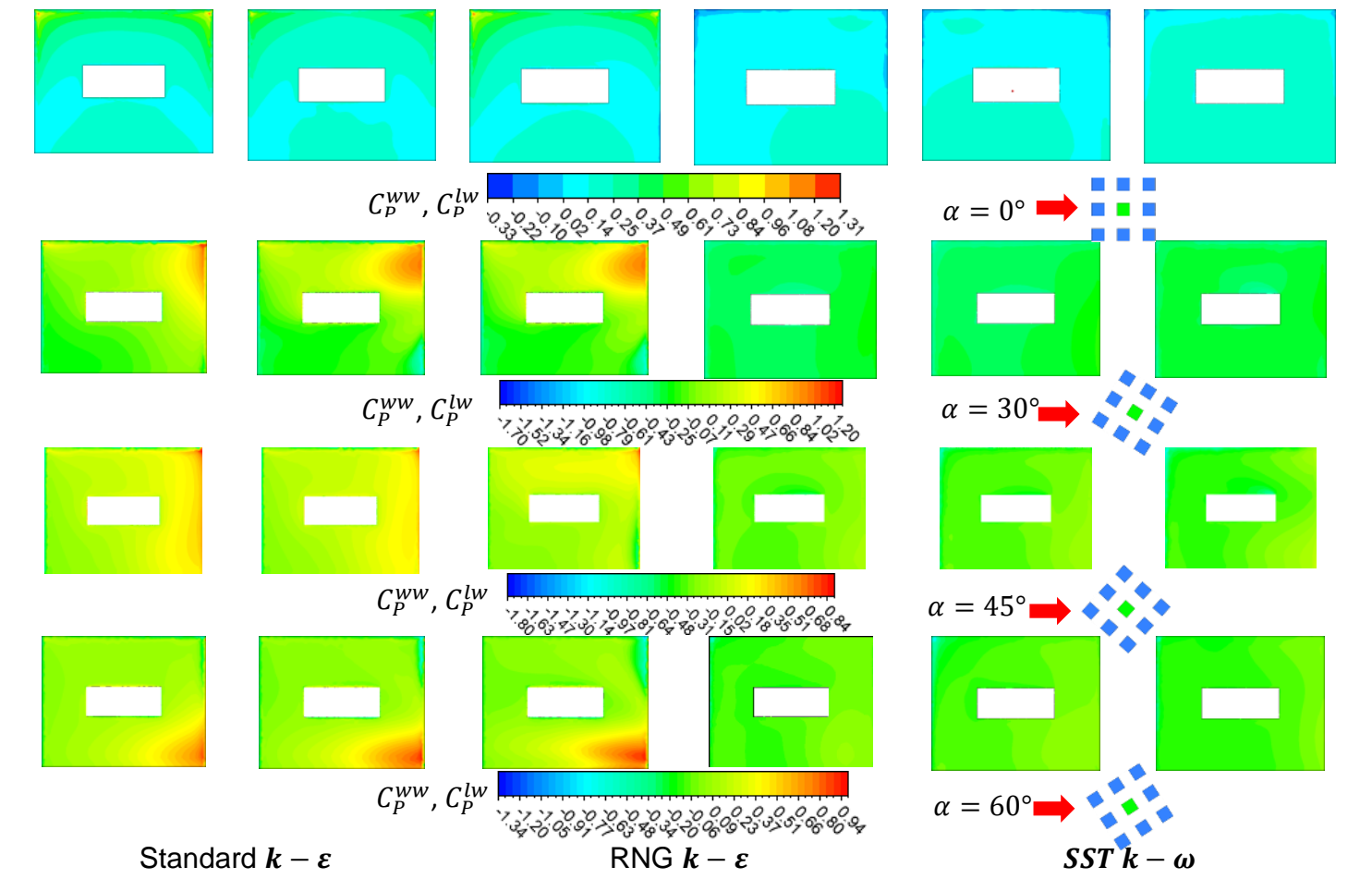

Figure 14 Distribution of the surface wind pressure over windward and leeward façades for a planar area ratio of 0.25 obtained by the standard $k-\varepsilon$ model with the Upwind scheme against wind angles of $0^{\circ}$ and $30^{\circ}$

In Figure 15(a), variation of the total pressure difference coefficient $\left(C_{P}^{\text {total }}\right)$ is plotted against different wind angles calculated by the standard $k-\varepsilon$, RNG $k-\varepsilon$, and $k-\omega$ SST models. Against the $0^{\circ}$ wind angle, a significant deviation in the value of $C_{P}^{\text {total }}$ can be seen between different turbulence models and the experimental results. While the experimental value of the total pressure difference coefficient is $C_{P}^{\text {total }}=0.171$, the standard $k-\varepsilon$ and RNG $k-\varepsilon$ models underpredict $C_{P}^{\text {total }}$ with values of 0.023 and 0.031 , respectively. The $k-\omega$ SST model predicts a negative total pressure difference coefficient of $C_{P}^{\text {total }}=-0.028$. Inaccurate prediction of the velocity field in the upstream and downstream cavities and underestimation of the momentum diffusion in these areas result in very low wind surface pressure difference coefficients over the windward and leeward façades against the normal wind angle.

In contrast, against the oblique wind angles, good agreements between the experimental and CFD results can be obtained, which is due to the increased velocity in the street canyon and the higher accuracy of the CFD model in prediction of the velocity fields. When the wind angle increases to $30^{\circ}$, the $C_{P}^{\text {total }}$ rises significantly as a result of the increased velocity in the windward cavity (see Figure 7). The experimental value of $C_{P}^{\text {total }}$ is 0.352 while the numerical predictions by 
the standard $k-\varepsilon$, RNG $k-\varepsilon, k-\omega$ SST models are respectively $0.385,0.351$, and 0.362 . The wind surface pressure difference drops uniformly when the wind angle elevates further to $45^{\circ}$ and $60^{\circ}$ while the associated experimental values of $C_{P}^{\text {total }}$ are 0.316 and 0.163 , respectively. Very close predictions are calculated by different turbulence models with values ranging between $0.31 \leq C_{P}^{\text {total }} \leq 0.334$ and $0.181 \leq C_{P}^{\text {total }} \leq 0.219$ against the wind angles of $45^{\circ}$ and $60^{\circ}$.

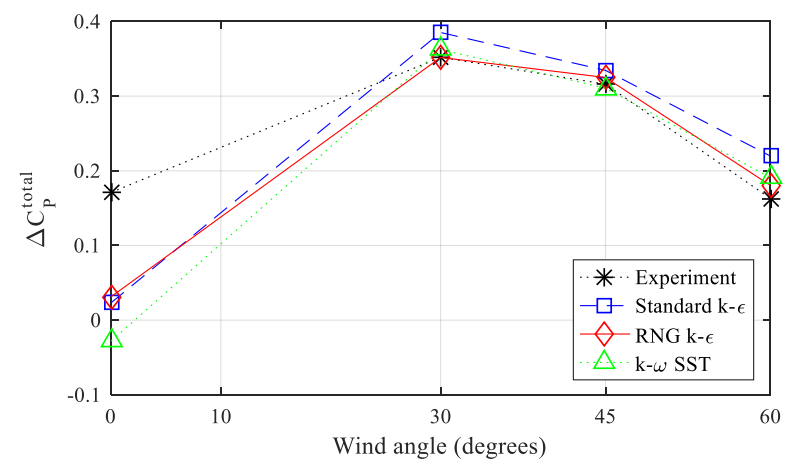

(a)

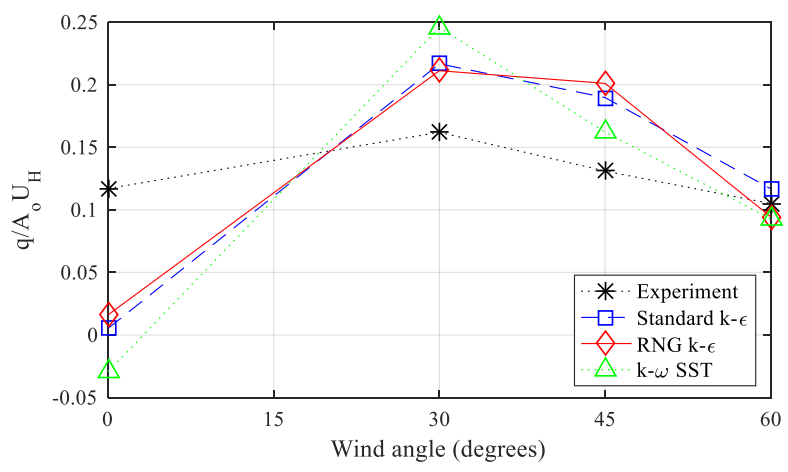

(b)

Figure 15 Variation of (a) total surface pressure difference coefficient $\left(\Delta C_{P}^{\text {total }}\right)$ and (b) crossing airflow rate $\left(\frac{q}{A_{0} U_{H}}\right)$ against different wind angles calculated by different turbulence models

\subsubsection{Airflow rate}

In Figure 15(b), the crossing airflow rate $\left(\frac{q}{A_{o} U_{H}}\right)$ calculated by different turbulence models are compared with the experimental values against different wind angles. The trend of variation of airflow rate is very similar to the variation of the total surface pressure difference $\left(C_{P}^{\text {total }}\right)$ as shown in Figure 15(a). In the case of the $0^{\circ}$ wind angle, all turbulence models predict near zero values for the crossing airflow rate, which are respectively $0.005,0.015$, and -0.029 for the standard $k-$ $\varepsilon$, RNG $k-\varepsilon$, and $k-\omega$ SST models. The negative crossing airflow rate calculated by the $k-\omega$ SST model indicates that the airflow enters the building from the leeward façade in the reverse direction of the free-stream flow. This is resulted due to the negative surface pressure difference coefficient calculated by the $k-\omega$ SST model, which is a driving force of the airflow through the building openings (see Figure 15(a)).

Against the wind angle of $30^{\circ}$, the $\frac{q}{A_{o} U_{H}}$ rises significantly to 0.162 , which is due to the higher velocity in the street canyon and the higher wind surface pressure over the windward façade (see Figure 7 and Figure 15(a)). In general, all turbulence models overestimate the crossing airflow rate with values of $0.216,0.21$, and 0.245 for the standard $k-\varepsilon$, RNG $k-\varepsilon$, and $k-\omega$ SST models, respectively.

Further increase in the wind angle results in a uniform decrease of the crossing airflow rate. The experimentally measured airflow rate is $\frac{q}{A_{O} U_{H}}=0.131$ against the wind angle of $45^{\circ}$. Again, all turbulence models overpredict the crossing airflow rate. In this case, the calculated airflow rates by the standard $k-\varepsilon$, RNG $k-\varepsilon$, and $k-\omega$ SST models are $0.189,0.201$, and 0.165 , respectively. The best agreement between the experimental and CFD results are observed 
against the wind angle of $60^{\circ}$ where the measured $\frac{q}{A_{o} U_{H}}$ is 0.104 and the predicted values by the standard $k-\varepsilon$, RNG $k-\varepsilon$, and $k-\omega$ SST models are respectively $0.116,0.095$, and 0.092 .

Comparison of the CFD accuracy in prediction of the crossing airflow rate and the wind surface pressure shows that the CFD model can predict the local wind surface pressure around the openings more accurate than the crossing airflow rate through the openings against the oblique wind angles. Hence, the crossing airflow rate predictions by the CFD model should be used with cautious for many applications such as building energy calculations.

\section{Conclusions}

Numerical results of cross-ventilation calculated by SRANS models were compared with experimental results obtained in an atmospheric boundary layer wind tunnel. Effects of different parameters, including mesh configuration, advection and diffusion terms discretization schemes, and turbulence models on the accuracy of CFD models to replicate the time-averaged velocity, TKE, wind surface pressure, and crossing airflow rate through the target building were studied.

It was shown that accuracy of the unstructured tetrahedral mesh with considerably lower cell numbers is comparable with the one for the structured hexahedral mesh created using the blocking technique while its implementation for different wind angles is more convenient with a noticeable lower computational time. Moreover, the diffusion discretization scheme showed to have negligible effect on the CFD accuracy while the advection discretization scheme was found to be more important. Against the normal wind angle a higher CFD accuracy was obtained by the first-order UP scheme while the second-order HR scheme performed better for the oblique wind angles. The well-known momentum diffusion underestimation of the SRANS models seems to be compromised with over-prediction of momentum in the wake regions by the UP schemes, which resulted to more accurate results against the normal wind angle. Despite, a better CFD solver convergence by the UP scheme, it generally overestimated the wind surface pressure and crossing airflow rates against different wind angles.

Furthermore, a very low accuracy was obtained by the standard $k-\varepsilon$, RNG $k-\varepsilon$, and $k-\omega$ SST models against the normal wind angle while none of the models could predict windward and leeward jets. Against the oblique wind angles, good agreements were obtained for the velocity and TKE distribution around the windward jet while low accurate results were observed in the regions far from the windward façade inside the building.

All turbulence models significantly underestimated the wind surface pressure and crossing airflow rate. Accuracy of these models was improved noticeably for the oblique wind angles where a higher wind velocity can be observed in the street canyons around the opening as a result of the channeling effect. Despite a very close agreement between the CFD and experimental results for the surface wind pressure against the oblique wind angles, all turbulence models noticeably overpredicted the crossing airflow rate. Hence, uncertainty of the CFD results for the crossing airflow rate should be considered when they are used for building performance applications such as building energy calculations. 
Future works will focus on the model enhancement of RANS turbulence models in order to improve the accuracy of CFD models for engineering applications. Furthermore, application of unsteady RANS and LES models for prediction of the cross-ventilation and airflow around the sheltered buildings at different urban configurations will be investigated.

\section{Acknowledgement}

Faculty of engineering of the University of Nottingham is acknowledged for the financial support. The authors would like to express their gratitude to Niigata Institute of Technology for financial support.

\section{References}

Akabayashi, S., Mochida, A., Tominaga, Y., Yoshida, M., \& Sakaguchi, J. (1996). Performance of new wind tunnel of Niigata Institute of Technology. Wind Engineers, JAWE, 1996(68), 95-106.

Allegrini, J., \& Carmeliet, J. (2017). Coupled CFD and building energy simulations for studying the impacts of building height topology and buoyancy on local urban microclimates. Urban Climate, 21, 278-305.

Allegrini, J., Dorer, V., \& Carmeliet, J. (2015). Coupled CFD, radiation and building energy model for studying heat fluxes in an urban environment with generic building configurations. Sustainable Cities and Society, 19(Supplement C), 385394. https://doi.org/https://doi.org/10.1016/j.scs.2015.07.009

Blocken, B. (2015). Computational Fluid Dynamics for urban physics: Importance, scales, possibilities, limitations and ten tips and tricks towards accurate and reliable simulations. Building and Environment, 91, 219-245.

CFX, A. (2011). Solver Theory Guide. Ansys. Inc., Canonsburg, PA.

Charisi, S., Waszczuk, M., \& Thiis, T. K. (2019). Determining building-specific wind pressure coefficients to account for the microclimate in the calculation of air infiltration in buildings. Advances in Building Energy Research, 1-22. https://doi.org/10.1080/17512549.2019.1596835

Chow, W. L., \& Rhie, C. M. (1982). A numerical study of the turbulent flow past an isolated airfoil with trailing edge separation. Joint Thermophysics, Fluids, Plasma and Heat Transfer Conference, St. Louis, MO.

Franke, J., Hirsch, C., Jensen, A. G., Krüs, H. W., Schatzmann, M., Westbury, P. S., ... Wright, N. G. (2004). Recommendations on the use of CFD in wind engineering. Cost Action C, 14, C1.

Indraganti, M. (2010). Adaptive use of natural ventilation for thermal comfort in Indian apartments. Building and Environment, 45(6), 1490-1507.

lqbal, Q. M. Z., \& Chan, A. L. S. (2016). Pedestrian level wind environment assessment 
around group of high-rise cross-shaped buildings: Effect of building shape, separation and orientation. Building and Environment, 101, 45-63.

Ishida, Y., Okaze, T., \& Mochida, A. (2018). Influence of urban configuration on the structure of kinetic energy transport and the energy dissipation rate. Journal of Wind Engineering and Industrial Aerodynamics, 183, 198-213.

Kanda, M. (2006). Large-eddy simulations on the effects of surface geometry of building arrays on turbulent organized structures. Boundary-Layer Meteorology, 118(1), 151-168.

King, M.-F., Khan, A., Delbosc, N., Gough, H. L., Halios, C., Barlow, J. F., \& Noakes, C. J. (2017). Modelling urban airflow and natural ventilation using a GPU-based lattice-Boltzmann method. Building and Environment, 125, 273-284.

Kurbatskii, A. F. (2001). Computational modeling of the turbulent penetrative convection above the urban heat island in a stably stratified environment. Journal of Applied Meteorology, 40(10), 1748-1761.

Launder, B. E., \& Spalding, D. B. (1974). The numerical computation of turbulent flows. Computer Methods in Applied Mechanics and Engineering, 3(2), 269-289.

Liu, J., Heidarinejad, M., Pitchurov, G., Zhang, L., \& Srebric, J. (2018). An extensive comparison of modified zero-equation, standard $k-\varepsilon$, and LES models in predicting urban airflow. Sustainable Cities and Society, 40, 28-43.

Malys, L., Musy, M., \& Inard, C. (2015). Microclimate and building energy consumption: study of different coupling methods. Advances in Building Energy Research, 9(2), 151-174. https://doi.org/10.1080/17512549.2015.1043643

Menter, F. R. (1994). Two-equation eddy-viscosity turbulence models for engineering applications. AIAA Journal, 32(8), 1598-1605.

Mirzaei, P. A., \& Haghighat, F. (2011). Pollution removal effectiveness of the pedestrian ventilation system. Journal of Wind Engineering and Industrial Aerodynamics, 99(1), 46-58.

Mirzaei, P. A., \& Haghighat, F. (2012). A procedure to quantify the impact of mitigation techniques on the urban ventilation. Building and Environment, 47, 410-420.

Mirzaei, P. A., \& Rad, M. (2013). Toward design and fabrication of wind-driven vehicles: Procedure to optimize the threshold of driving forces. Applied Mathematical Modelling, 37(1), 50-61. https://doi.org/https://doi.org/10.1016/j.apm.2011.11.037

Mochida, A, Tominaga, Y., Murakami, S., Yoshie, R., Ishihara, T., \& Ooka, R. (2002). Comparison of various ke models and DSM applied to flow around a high-rise building. Wind and Structures, 5(2-4), 227-244.

Mochida, Akashi, Yoshino, H., Miyauchi, S., \& Mitamura, T. (2006). Total analysis of cooling effects of cross-ventilation affected by microclimate around a building. Solar 
Energy, 80(4), 371-382.

Mochida, Akashi, Yoshino, H., Takeda, T., Kakegawa, T., \& Miyauchi, S. (2005). Methods for controlling airflow in and around a building under cross-ventilation to improve indoor thermal comfort. Journal of Wind Engineering and Industrial Aerodynamics, 93(6), 437-449. https://doi.org/http://dx.doi.org/10.1016/j.jweia.2005.02.003

Montazeri, H., \& Blocken, B. (2013). CFD simulation of wind-induced pressure coefficients on buildings with and without balconies: validation and sensitivity analysis. Building and Environment, 60, 137-149.

Murakami, S., Mochida, A., \& Hayashi, Y. (1990). examining the $k-\epsilon$ model by means of a wind tunnel test and large-eddy simulation of the turbulence structure around a cube. Journal of Wind Engineering and Industrial Aerodynamics, 35, 87-100.

Phan, L., \& Lin, C.-X. (2019). CFD-based response surface methodology for rapid thermal simulation and optimal design of data centers. Advances in Building Energy Research, 1-23. https://doi.org/10.1080/17512549.2019.1622154

Quan, Y., Tamura, Y., Matsui, M., Cao, S., Yoshida, A., \& Xu, S. (2007). Interference effect of a surrounding building group on wind loads on flat roof of low-rise building: Part I, Distribution of local wind pressure coefficient. Wind Engineers, JAWE, 32, 211-212.

Ramponi, R., \& Blocken, B. (2012a). CFD simulation of cross-ventilation flow for different isolated building configurations: validation with wind tunnel measurements and analysis of physical and numerical diffusion effects. Journal of Wind Engineering and Industrial Aerodynamics, 104, 408-418.

Ramponi, R., \& Blocken, B. (2012b). CFD simulation of cross-ventilation for a generic isolated building: impact of computational parameters. Building and Environment, 53, 34-48.

Razak, A. A., Hagishima, A., Ikegaya, N., \& Tanimoto, J. (2013). Analysis of airflow over building arrays for assessment of urban wind environment. Building and Environment, 59, 56-65.

Shirzadi, M., Mirzaei, P. A., \& Naghashzadegan, M. (2017). Improvement of k-epsilon turbulence model for CFD simulation of atmospheric boundary layer around a highrise building using stochastic optimization and Monte Carlo Sampling technique. Journal of Wind Engineering and Industrial Aerodynamics, 171. https://doi.org/10.1016/j.jweia.2017.10.005

Shirzadi, M., Mirzaei, P. A., \& Naghashzadegan, M. (2018). Development of an adaptive discharge coefficient to improve the accuracy of cross-ventilation airflow calculation in building energy simulation tools. Building and Environment, 127. https://doi.org/10.1016/j.buildenv.2017.10.019 
Shirzadi, M., Mirzaei, P. A., Naghashzadegan, M., \& Tominaga, Y. (2018). Modelling enhancement of cross-ventilation in sheltered buildings using stochastic optimization. International Journal of Heat and Mass Transfer, 118. https://doi.org/10.1016/j.ijheatmasstransfer.2017.10.107

Shirzadi, M., Naghashzadegan, M., \& A. Mirzaei, P. (2018). Improving the CFD modelling of cross-ventilation in highly-packed urban areas. Sustainable Cities and Society, 37. https://doi.org/10.1016/j.scs.2017.11.020

Shirzadi, Mohammadreza, Naghashzadegan, M., \& Mirzaei, P. A. (2019). Developing a framework for improvement of building thermal performance modeling under urban microclimate interactions. Sustainable Cities and Society, 44, 27-39.

Shirzadi, Mohammadreza, Tominaga, Y., \& Mirzaei, P. A. (2019). Wind tunnel experiments on cross-ventilation flow of a generic sheltered building in urban areas. Building and Environment, 158, 60-72. https://doi.org/https://doi.org/10.1016/j.buildenv.2019.04.057

Tominaga, Y. (2015). Flow around a high-rise building using steady and unsteady RANS CFD: Effect of large-scale fluctuations on the velocity statistics. Journal of Wind Engineering and Industrial Aerodynamics, 142, 93-103.

Tominaga, Y., Akabayashi, S., Kitahara, T., \& Arinami, Y. (2015). Air flow around isolated gable-roof buildings with different roof pitches: Wind tunnel experiments and CFD simulations. Building and Environment, 84, 204-213.

Tominaga, Y., \& Blocken, B. (2015). Wind tunnel experiments on cross-ventilation flow of a generic building with contaminant dispersion in unsheltered and sheltered conditions. Building and Environment, 92, 452-461.

Tominaga, Y., Mochida, A., Yoshie, R., Kataoka, H., Nozu, T., Yoshikawa, M., \& Shirasawa, T. (2008). AlJ guidelines for practical applications of CFD to pedestrian wind environment around buildings. Journal of Wind Engineering and Industrial Aerodynamics, 96(10), 1749-1761.

Tominaga, Y., Okaze, T., \& Mochida, A. (2018). Wind tunnel experiment and CFD analysis of sand erosion/deposition due to wind around an obstacle. Journal of Wind Engineering and Industrial Aerodynamics, 182, 262-271.

Tominaga, Y., \& Stathopoulos, T. (2011). CFD modeling of pollution dispersion in a street canyon: Comparison between LES and RANS. Journal of Wind Engineering and Industrial Aerodynamics, 99(4), 340-348.

Tominaga, Y., \& Stathopoulos, T. (2017). Steady and unsteady RANS simulations of pollutant dispersion around isolated cubical buildings: Effect of large-scale fluctuations on the concentration field. Journal of Wind Engineering and Industrial Aerodynamics, 165, 23-33.

Tominaga, Y., \& Stathopoulos, T. (2018). CFD simulations of near-field pollutant 
dispersion with different plume buoyancies. Building and Environment, 131, 128139.

Tong, Z., Chen, Y., \& Malkawi, A. (2016). Defining the Influence Region in neighborhood-scale CFD simulations for natural ventilation design. Applied Energy, 182, 625-633.

van Hooff, T., Blocken, B., \& Tominaga, Y. (2017). On the accuracy of CFD simulations of cross-ventilation flows for a generic isolated building: Comparison of RANS, LES and experiments. Building and Environment, 114(Supplement C), 148-165. https://doi.org/https://doi.org/10.1016/j.buildenv.2016.12.019

Yakhot, V., \& Orszag, S. A. (1986). Renormalization-group analysis of turbulence. Physical Review Letters, 57(14), 1722.

Yamamoto, M., Kasai, M., Okaze, T., Hanaoka, K., \& Mochida, A. (2018). Analysis of climatic factors leading to future summer heatstroke risk changes in Tokyo and Sendai based on dynamical downscaling of pseudo global warming data using WRF. Journal of Wind Engineering and Industrial Aerodynamics, 183, 187-197.

Yoshie, R., Mochida, A., Tominaga, Y., Kataoka, H., Harimoto, K., Nozu, T., \& Shirasawa, T. (2007). Cooperative project for CFD prediction of pedestrian wind environment in the Architectural Institute of Japan. Journal of Wind Engineering and Industrial Aerodynamics, 95(9), 1551-1578.

Zhang, R., Mirzaei, P. A., \& Jones, B. (2018). Development of a dynamic external CFD and BES coupling framework for application of urban neighbourhoods energy modelling. Building and Environment, 146, 37-49. 